Innales
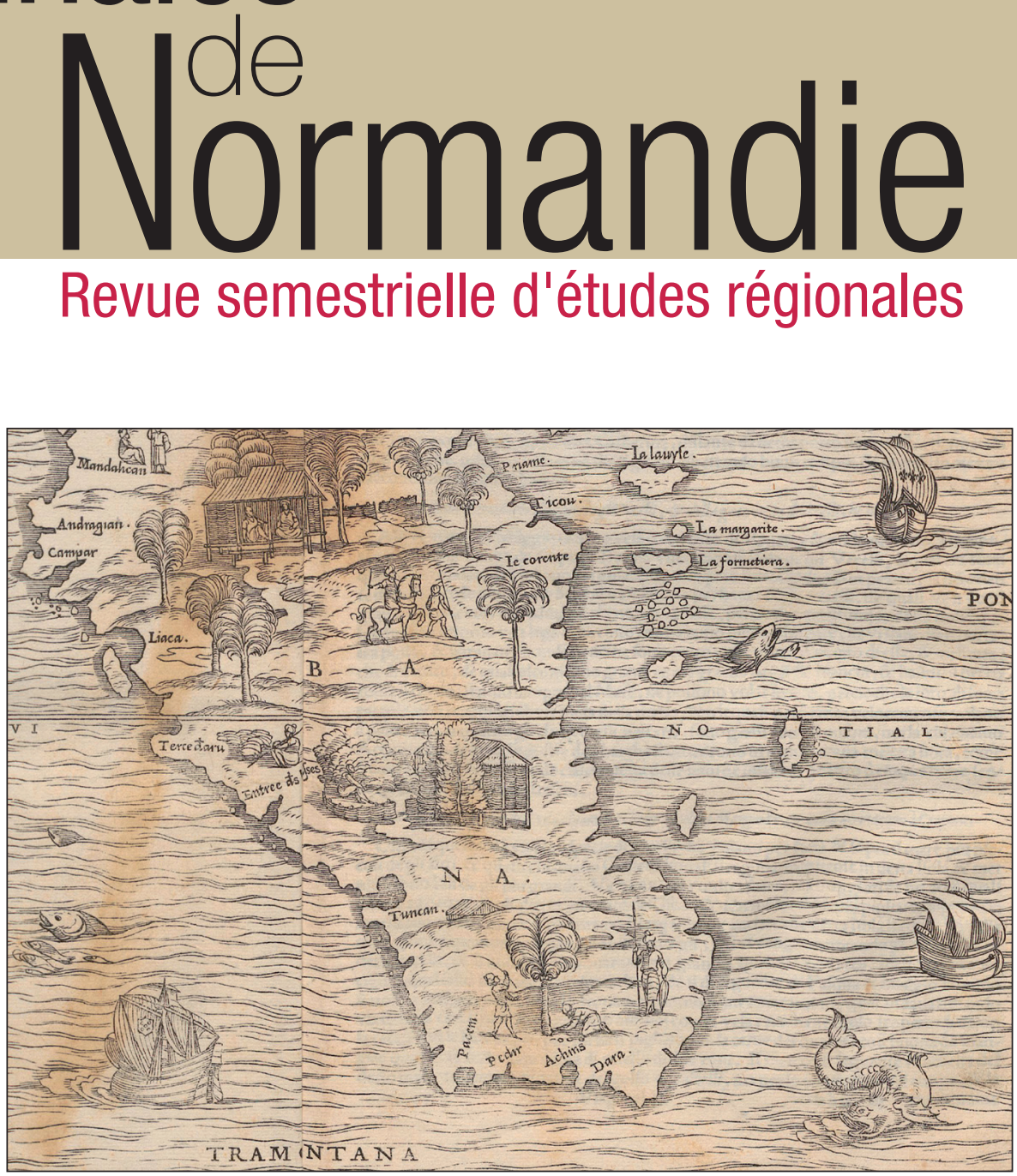

Ouvrage publié avec le concours : de l'université de Caen Normandie de la Maison de la Recherche en Sciences Humaines de Caen de la Ville de Caen du Ministère de la Culture et de la Communication 


\title{
Le Discours d'un grand capitaine de Dieppe. Traduction et édition d'un document normand de 1539
}

\author{
GuILLAUME LELIÈVRE*
}

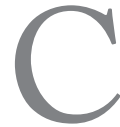

ETTE CONTRibution constitue l'étude historique liée à l'édition numérique du Discours d'un grand capitaine de Dieppe, consultable prochainement à l'adresse : http://unicaen.fr/recherche/mrsh/maritime/projet/ rin. Celle-ci a été réalisée, grâce aux outils développés par le pôle Document numérique de la MRSH de l'université de Caen Normandie, dans le cadre du projet NORMONDE : "Empires en Seine. Les Normands acteurs de la mondialisation $\left(\mathrm{Ix}^{\mathrm{e}}-\mathrm{XXI}^{\mathrm{e}}\right.$ siècle) $»^{1}$. Le Discours d'un grand capitaine de Dieppe réunit des descriptions de quatre territoires différents et très éloignés géographiquement : la côte nord-américaine, celle du Brésil, celle de l'Afrique du cap Vert au Congo, et l'île de Sumatra. Ce texte, issu d'un manuscrit original rédigé en français aujourd'hui perdu, est connu dès le Xvi ${ }^{\mathrm{e}}$ siècle grâce à l'érudit Giovanni Batista Ramusio, qui le traduit en italien et le publie dans le troisième volume de ses Navigationi et viaggi paru à Venise en 1556. Depuis le XIX ${ }^{\mathrm{e}}$ siècle, trois traductions en français - ou plus exactement trois rétroversions ${ }^{2}$ - et une traduction en anglais ont été réalisées.

Ce document très riche nous intéresse du point de vue historique : peu ou mal connu, il n'est plus utilisé par l'historiographie depuis longtemps, même s'il est mentionné ici ou là. Afin de mieux le comprendre, il nous est apparu nécessaire de le réinterroger avec un nouveau regard et dans une nouvelle perspective : celle du rôle des Normands dans la première mondialisation au début du XVI ${ }^{\mathrm{e}}$ siècle. Pour cela, nous sommes partis d'une nouvelle traduction, effectuée par une universitaire italianophone, Mariella Colin ${ }^{3}$, à partir de

* Normandie Univ, UNICAEN, CNRS, MRSH, 14000 Caen, France.

1 Ce projet, financé par la Région Normandie, réunit les laboratoires universitaires du CRAHAM (Caen), du GRHis (Rouen), d'IDEES (Le Havre), du PEMAR-MRSH (Caen / Le Havre) et du CRHIA (Nantes-La Rochelle).

2 C'est-à-dire traduire une nouvelle fois un texte, mais dans la langue dans laquelle il a été rédigé initialement.

3 Professeure de littérature et civilisation de langue italienne ( $\mathrm{XIX}^{\mathrm{e}}$-XX ${ }^{\mathrm{e}}$ siècle), équipe ERLIS 4254, Université de Caen Normandie. Nous lui adressons ici nos remerciements. 
l'édition princeps de 1556. Cela nous a permis de mener une étude historique du texte et une analyse de son contenu, qui ont donné lieu à une annotation scientifique et permettent d'aboutir à des hypothèses sur la datation et le contexte de rédaction, ainsi que sur l'identification de l'auteur et du fameux " grand capitaine de Dieppe».

\section{RAMUSIO ET SON RECUEIL : LE « MONUMENT RAMUSIEN » ${ }^{4}$}

Giovanni Batista Ramusio est célèbre pour avoir publié dans les années 1550 un recueil de récits de voyages intitulé Navigationi et viaggi. Il s'agit d'un événement fondateur dans l'histoire de la géographie moderne. Sa vie et son œuvre ont été largement étudiés, et ont fait récemment l'objet d'une thèse ${ }^{5}$. Ramusio est né à Trévise en 1485. Il acquiert une solide formation humaniste, linguistique et géographique à Padoue, où il fréquente l'école de Pietro Pomponazzi, dit Pierre de Mantoue. En 1505, il entre au service de la Sérénissime République de Venise, occupant tour à tour les fonctions de secrétaire de la Chancellerie, du Sénat puis du Conseil des Dix, organe suprême des institutions vénitiennes. À ce titre, il a pu participer à plusieurs ambassades $^{6}$, mais le seul voyage qui peut lui être attribué avec certitude l'a mené en France en 1505-1507, en tant que secrétaire de l'ambassadeur de Venise, Alvise Mocenigo. Par ses fonctions, il se trouve en relation avec un dense réseau de collaborateurs (diplomates, voyageurs et correspondants étrangers) à même de lui fournir des témoignages et des récits de première main. Il fait également partie d'un brillant cercle d'humanistes comprenant par exemple le cardinal Pietro Bembo, historiographe de la République de Venise à partir de 1529 puis conservateur de la Biblioteca Marciana, et le célèbre médecin véronais Girolamo Fracastoro, dit Fracastor (Hieronymus Fracastorius), astronome et astrologue réputé7.

4 S. Albertan-Coppola, M.-C. Gomez-Géraud, « La collection des Navigationi et viaggi (15501559) de Giovanni Battista Ramusio : mécanismes et projets d'après les paratextes ", Revue des études italiennes, $\mathrm{n}^{\circ} 36,1990$, p. 62.

5 F. Lejosne, Giovanni Battista Ramusio et la constitution d'un savoir géographique à Venise au XVI ${ }^{e}$ siècle : parcours scientifique et horizon politique, thèse de doctorat en études italiennes sous la direction de R. Descendre, ENS Lyon, novembre 2016 (publication prévue en 2019 chez Droz). Nous remercions Fiona Lejosne, qui nous a permis l'accès à sa version de soutenance. Elle est également l'auteur de plusieurs articles sur Ramusio.

6 Dans A i lettori qui ouvre le second volume paru en 1559 (n. p.), l'imprimeur Tommaso Giunti évoque des voyages effectués au service de la Sérénissime République durant sa jeunesse in diuerse paesi.

7 Voir Girolamo Fracastoro. Fra medicina, filosofia e scienze della natura, A. PASTORE, E. PeruzzI (éd.), Florence, Olschki, 2006 et la réédition de son œuvre principale : De sympathia et antipathia rerum, C. Pennuto (éd.), Rome, Edizioni di storia e letteratura, 2008. 
C'est ce dernier qui l'encourage à entreprendre un " projet éditorial d'envergure inouie $»^{8}:$ l'objectif, affiché dès la dédicace du premier volume qui lui est consacrée, est la mise à jour de l'image de l'œkoumène et du savoir géographique, en compilant toutes les sources textuelles pouvant être rassemblées. C'est pour ces deux aspects que les Navigationi et viaggi sont la plupart du temps cités dans les travaux traitant de l'émergence de l'histoire globale et de la première mondialisation : du fait de l'échelle adoptée, avec l'ambition de décrire l'intégralité du monde connu, et de la variété des sources utilisées. Logiquement, celles-ci s'avèrent hétérogènes : récits de voyage (en majorité), lettres, relations officielles, textes « géographiques » divers, etc. Afin de former un ensemble cohérent et fiable, l'un des critères suivis par Ramusio est de sélectionner prioritairement des documents faisant état d'une expérience directe, au sens premier de l'autopsie : le fait de voir de ses propres yeux.

Ramusio entreprend ce travail colossal de compilation vraisemblablement au cours des années 1520, aidé en cela par son fils, Paolo', et par l'imprimeur Tommaso Giunti. Mais il ne suffit pas de raccogliere, E' metter insieme (recueillir / collecter et mettre ensemble / rassembler), comme le dit Ramusio lui-même ${ }^{10}$. Certains textes lui parviennent en espagnol ou en français par exemple, et doivent être traduits en italien, ce qui permet là aussi de donner une homogénéité à l'ensemble du recueil. Sur la page de titre du troisième volume publié en 1556 apparaît la mention : diuerse Relationi, tradotte di Lingua Spagnuola \& Francese nella nostra. Dans les deux éditions suivantes (1565 et 1606), elle est modifiée en diuerse Relationi, tradotte dal Ramusio di Lingua Spagnuola \& Francese nella nostra Italiana. Par ailleurs, Tommaso Giunti loue la connaissance que Ramusio avait du français et de l'espagnol ${ }^{11}$; il serait donc l'auteur des traductions. Sa maîtrise du français semble ne faire aucun doute, au point qu'il aurait été l'interprète du doge ${ }^{12}$. Enfin, il est cité comme traducteur au sein de la chancellerie par Marino Sanudo, un patricien qui, dans ses Diarii, prit note de manière extrêmement détaillée des événements

8 F. Lejosne, « Les lieux du compilateur : les Navigationi et viaggi de G.B. Ramusio (1550-1559)», Belgeo. Revue belge de géographie, 2 | 2014, en ligne : http://belgeo.revues.org/12909.

9 Lui-même auteur d'un ouvrage publié à Venise en 1604 : Della guerra di Costantinopoli per la restitutione de gl'imperatori Comneni fatta da' signori Venetiani, et Francesi, l'anno 1204.

10 Dans la dédicace à Girolamo Fracastoro (n. p.) et dans le Discorso sopra alcune lettere, et Navigationi fatte per li Capitani dell 'Armate delli Serenissimi Re di Portogallo, uerso le Indie Orientali (fol. $129 \mathrm{v}$ ) du premier volume paru en 1550 .

11 Dans A i lettori (vol. II, 1559, n. p.) : [...] che fece medesimamente acquisto della lingua Francese, \& della Spagnuola, hauendole si ben familiari, come la sua propria natia:\& essene seruito nel tradur molti relationi stampate nel Primo et nel Terzo volume.

12 Voir G.B. PARKs, « Ramusio’s Literary History », Studies in Philology, vol. LII, n², avril 1955, p. 129-130: «At any rate, Ramusio was marked thereafter in Venice as useful in dealing with the French: he received and interpreted for French envoys, and, according to an admirer, he spoke French like a Parisian and was French interpreter for the Doge ». L'« admirer » est Franciscus Asulanus, dans sa dédicace aux Decas Tertia de Tite-Live parues en 1519. L'humaniste Giovanni Francesco Torresano ou Francesco d'Asola était imprimeur-libraire à Venise. 
politiques de la vie vénitienne entre 1496 et 1533. Siégeant lui-même au Sénat, il est une source de première main très fiable ${ }^{13}$.

Ramusio avoue avoir souffert face à la diversité des langues utilisées par les auteurs et aussi parce que les exemplaires qui lui sont parvenus étaient défectueux ${ }^{14}$. Des erreurs de traduction, sur des chiffres par exemple, restent envisageables, en raison de la mauvaise qualité des manuscrits ou à cause de lectures erronées.

Dans la Chrétienté, l'exploration des côtes de l'Afrique puis des rives de l'océan Indien par les Portugais, ainsi que les voyages de Christophe Colomb et de ses successeurs outre-Atlantique ont bouleversé les représentations anciennes de l'orbis terrarum héritées de l'Antiquité et du Moyen Âge. Outre les œuvres de Strabon, Pomponius Mela ou Denis le Périégète redécouvertes au cours des années 1470, "la véritable "bible" géographique de la Renaissance a été la Géographie de Ptolémée ${ }^{15}$, corrigée et enrichie progressivement au fur et à mesure des découvertes ${ }^{16}$. Au Moyen Âge sont apparus des récits fabuleux tels que le Livre des merveilles de Marco Polo ou les Voyages de Jean de Mandeville, ainsi que de nombreuses encyclopédies, œuvres à caractère encyclopédique et compilations comme l'Imago Mundi de Pierre d'Ailly ou la Cosmographie de Pie II. Ces diverses publications ont fait perdurer de nombreux mythes tenaces, des légendes issues de l'Antiquité, peuplées de monstres, de merveilles et de prodiges, surtout en Inde (griffons, géants, panoplie d'animaux et hommes monstrueux), sans compter l'influence du christianisme (Paradis terrestre, fabuleux pays d'Ophir, royaume de Gog et Magog, Prêtre Jean, Brasil, Antilia, Sept-Cités, saint Brendan...). Bref, toute une géographie fantastique et quelque peu fantaisiste.

Les humanistes s'efforcent alors de dresser une sorte de bilan épistémologique, par l'intermédiaire de cartes, d'atlas, mais aussi de recueils de voyages, qui rassemblent les récits des " navigations modernes ${ }^{17}$ dans des contrées jusqu'alors inconnues et permettent de faire progresser la connaissance de la Terre. Après les Décades de Pierre Martyr d'Anghiera, qui relatent les premiers voyages de Christophe Colomb et de ses successeurs, et le Mundus Novus attribué à Amerigo Vespucci, paraît à Vicence en 1507 le premier véritable recueil

13 M. Sanudo, Diarii, R. Fulin, F. Stefani, N. Barozzi, G. Berchet et M. Allegri (éd.), Venise, Visentini, 1879-1902. Voir la thèse de F. Lejosne.

14 la diuersitá delle lingue, nelle quali detti auttori hanno scritto [...] che gli essemplari che mi son venuti alle mani, erano estremamente guasti, \& scorretti (dédicace à Girolamo Fracastoro, vol. I, 1550 , n. p.).

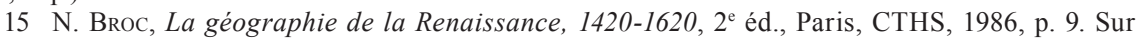
l'historique de la Géographie de Ptolémée, voir chap. I : «Ptolémée et Christophe Colomb », p. 9-19.

16 Il ne faut toutefois pas omettre le rôle précurseur de la cartographie médiévale arabe : dès le $\mathrm{XII}^{\mathrm{e}}$ siècle, Al-Idrisi, à la cour du roi normand Roger II de Sicile, avait initié la correction de la géographie de Ptolémée.

17 Les nauigationi moderne selon Ramusio dans le Discorso d'un gran capitano, vol. III, 1556, fol. 423 . 
de voyages : les Paesi novamente retrovatie Novo Mondo da Alberico Vesputio Florentino intitulato, du compilateur Fracanzio da Montalboddo. Contrairement à ce que laisserait penser son titre, il n'est pas consacré uniquement à Vespucci et au Brésil : on y trouve aussi les récits des explorations portugaises en Afrique, dans l'océan Indien, et même en Amérique du Nord. Ce recueil (traduit en français dès 1515 sous le titre S'ensuyt le Nouveau monde...) dresse en quelque sorte l'état des découvertes au début du XvI ${ }^{\mathrm{e}}$ siècle et constitue, « avec la Cosmographia Introductio de Waldseemüller, qui voit le jour la même année, [...] une des principales sources des géographes de la première Renaissance $»^{18}$.

Ces premières publications visent, sans plus de prétention, à faire connaître aux lecteurs ces terres nouvellement découvertes. Un nouveau pas est franchi avec la parution à Bâle en 1532 du Novus Orbis Regionum ou Recueil de Grynaeus, du nom de son éditeur : il s'agit de « la plus importante collection de voyages de la première Renaissance $»^{19}$, qui reprend en le développant et en le mettant à jour le recueil de Montalboddo. L'ensemble est compilé par le savant Johann Huttich et enrichi d'une mappemonde réalisée et commentée par le cosmographe Sébastien Münster. L'une de ses principales caractéristiques est de montrer aux lecteurs l'apport de tous ces voyages d'exploration en comparaison avec les connaissances héritées de l'Antiquité et, par conséquent, la supériorité des Modernes sur les Anciens.

Dans sa dédicace à Girolamo Fracastoro qui ouvre son premier volume paru en 1550, Ramusio explique lui-même son but : « Mais la raison qui me fit volontiers prendre de la peine à cette ouvre fut que, voyant et considérant les planches de la Géographie de Ptolémée, où sont décrites l'Afrique et l'Inde, être très imparfaites par rapport à la grande connaissance que l'on a aujourd'hui de ces régions, j'ai estimé qu'il serait précieux et peut-être profitable au monde de mettre ensemble les récits des auteurs de notre temps qui sont allés dans ces parties du monde et dont ils ont parlé minutieusement $»^{20}$. Ramusio ne se contente pas de réunir des textes connus : il y ajoute des inédits, tels que le Discorso d'un gran capitano, le récit du premier voyage de Jacques Cartier (1534) ${ }^{21}$ ou celui de Giovanni Verrazano $(1524)^{22}$, mais aussi

18 N. Broc, La géographie de la Renaissance..., op. cit., p. 27.

19 Ibid., p. 29.

20 Ma la cagione che mi fece affaticar volentieri in questa opera, fu, che vedendo, \& considerando le tauole della geographia di Tolomeo, doue si decriue l'Africa, \& la India esser molto imperfette, rispetto alla gran cognitione che si ha hoggi di quelle regioni, ho stimato douer esser caro, \& forse non poco vtile al mondo il mettere infieme le narrationi de gli scrittori de' nostri tempi, che sono stati nelle sopradette parti del mondo, \& di quelle han parlato minutamente (All'eccellentiss. M. Hieronimo Fracastoro, vol. I, 1550, n. p.).

21 On ne connaît effectivement le premier voyage de Cartier que grâce au texte publié par Ramusio. Sa traduction du récit du second voyage n'était pas inédite puisque le Brief récit et succinte narration de la navigation faite ès isle du Canada était paru à Paris en 1545.

22 Il s'agit bien là aussi de la première relation imprimée de ce voyage, même si cette version est incomplète car il y manque, entre autres, la précieuse partie « cosmographique » (distances parcourues, dimensions et situation du nouveau continent) présente à la fin du manuscrit Cèllere, considéré comme le 
plusieurs « discours » dont il est l'auteur, notamment un Discorso sopra la terra ferma delle Indie Occidentali dette del Lauorador, de los Bacchalaos, E̋ della nuoua Francia qui ouvre la «partie » consacrée à la Nuova Francia dans le troisième volume. A deux exceptions près, ces discours servent seulement à introduire les textes qui suivent, à les mettre en relation et à les commenter. Ramusio a aussi à plusieurs reprises mis par écrit des entretiens oraux avec des témoins directs, tels un pilote portugais commentant la navigation du Carthaginois Hannon et un marchand persan venu commercer à Venise.

Pour la première fois, tous ces documents sont organisés selon une logique spatiale, du moins à grands traits, car il existe des exceptions à la tripartition apparente : le premier volume est consacré à l'Afrique et aux Indes orientales, le second à l'Asie centrale, à la Russie et aux mers polaires, et le troisième à l'Amérique ${ }^{23}$. Par rapport aux recueils précédents, organisés de manière chronologique, il s'agit d'une caractéristique nouvelle. Ramusio a-t-il souhaité ainsi effectuer un découpage " géopolitique ", ou plutôt épistémologique, ou les deux à la fois ? Dans la première hypothèse, le premier et le troisième volume sont consacrés respectivement aux aires d'influence portugaise et espagnole, et le second rappelle le rôle joué historiquement par Venise dans l'établissement des relations avec le monde oriental. Dans la seconde, chaque volume désignerait un lieu de production du savoir géographique : le Portugal, Venise et l'Espagne. Mais l'on peut y voir aussi une répartition correspondant à une division du monde en fonction de son exploration par chacune de ces trois puissances, même si tous les voyages relatés dans un même volume n'ont pas forcément été organisés par la puissance concernée. Par exemple, le troisième volume se termine par une "partie » consacrée à la Nuova Francia qui, après un discours introductif de Ramusio, contient quatre récits «français » : trois expéditions réalisées au nom de François Ir - le premier voyage de Verrazano et les deux premiers de Cartier - et le Discorso d'un gran capitano.

Quoi qu'il en soit, après de longues années passées à collecter, rassembler et parfois traduire une soixantaine de textes disparates par leur célébrité, leur origine ou leur époque de production ${ }^{24}$, Ramusio, de manière anonyme, publie en 1550 à Venise le premier volume des Navigationi et viaggi. Celui-ci rencontre un vif succès et se trouve réédité dans une version revue et augmentée

meilleur et le plus complet, mais qui ne fut découvert qu'en 1909. Aussi, pendant les trois siècles et demi qui ont précédé cette découverte, c'est la version publiée par Ramusio qui fut traduite en plusieurs langues et qui servit de document de base pour étudier le voyage d'exploration de Verrazano. Le manuscrit Cèllere a été publié par J. Habert, M. Mollat du Jourdin, Giovanni et Girolamo Verrazano, navigateurs de François $I^{e r}$, Paris, Imprimerie nationale, 1982, p. 11-49.

23 Les sommaires des trois volumes sont consultables à l'adresse : https://digi.ub.uni-heidelberg. de/diglit/ramusio1554ga.

24 Des récits inédits comme celui de Léon l'Africain, de Cartier ou de Verrazano figurent aux côtés de ceux de voyageurs célèbres plus ou moins anciens tels que Hannon, Marco Polo, Vespucci, Pigafetta, Vasco de Gama, Cabral ou Cortés, mais aussi de personnages obscurs et anonymes comme un pilote portugais ou un capitaine espagnol. 
dès $1554^{25}$. Le troisième, incluant le Discorso d'un gran capitano, paraît en 1556 , et connaît deux autres éditions en 1565 et en 1606. La publication du second volume se trouve retardée par deux événements survenus l'année suivante : l'incendie de l'imprimerie Giunti et la mort de Ramusio, à Padoue, le 10 juillet 1557 . Il voit finalement le jour en $1559^{26}$, amputé de certains éléments, mais avec la première mention de l'identité du compilateur, indiquée dans l'adresse aux lecteurs signée par l'éditeur Tommaso Giunti. Un quatrième volume était prévu mais ne sera jamais publié. L'œuvre de Ramusio fut poursuivie et augmentée après sa mort, même si l'organisation géographique céda la place à des exigences d'équilibre entre les trois volumes ${ }^{27}$.

Ramusio ne possédait sans doute pas la maîtrise technique nécessaire à la cartographie. Il a donc travaillé avec plusieurs cartographes, principalement celui qui est devenu son proche collaborateur : Giacomo Gastaldi. Né vers 1500 à Villafranca, dans le Piémont, il s'installe en 1539 à Venise, où il devient un célèbre cartographe et travaille pour le compte de la Sérénissime République, jusqu'à sa mort en 1566. Il produit des globes, publie des planisphères et notamment en 1548 une édition de la Géographie de Ptolémée contenant des cartes réalisées à partir de 1542, dont une Carta Marina Nova Tabula. En 1553, il est chargé de réaliser les cartes qui figurent dans la Sala dello Scudo du Palais des Doges. Il est aussi l'auteur d'un ouvrage paru à Venise en 1562 : Universale descrittione del mondo, descritta da Giacomo de' Castaldi piamontese. I1 lie connaissance avec Ramusio à la fin des années 1540, lorsqu'il commence à enseigner la cosmographie à son fils, Paolo. Douze cartes lui sont attribuées dans le recueil de Ramusio. Trois sont publiées dans le premier volume dans l'édition de 1554 (Afrique et Arabie; Inde ; Asie du Sud-Est ${ }^{28}$ ) et neuf dans le troisième volume imprimé en $1556^{29}$ : Isola Spagnuola (Hispaniola, fol. 44); un plan de Mexico-Tenochtitlan (fol. 308v) ; une vue de Cuzco (fol. 411412) ; La terra de Hochelaga nella Nova Francia (fol. 446-447) ; Universale della parte del mondo nuovamente ritrovata (Amérique, fol. 455-456) ; ainsi que les quatre cartes contenues dans le Discorso d'un gran capitano: La Nuova Francia (fol. 424-425), Brasil (fol. 427-428), Parte de l'Africa (fol. 430-431) et Taprobana (Sumatra, fol. 433-434).

25 Il connut six éditions entre 1550 et 1613 et fut traduit en français par Jean Temporal dès 1556 sous le titre Historiale description de l'Afrique.

26 Il connut quatre éditions entre 1559 et 1606.

27 Ainsi, à la fin du troisième volume consacré jusque-là à l'Amérique, ont été ajoutés dans l'édition de 1606 le récit du voyage du marchand vénitien Cesare Federici aux Indes orientales ou encore des voyages d'explorations hollandais et zélandais dans les mers glacées du nord de l'Europe.

28 Reproduites dans La fabrique de l'océan Indien. Cartes d'Orient et d'Occident (Antiquité$X V I^{e}$ siècle), E. Vagnon, É. Vallet (éd.), Paris, Publications de la Sorbonne, 2017, p. 172, 190 et 218. La première édition de 1550 contient seulement cinq plans d'églises et une carte illustrant le parcours du Nil.

29 Le second ne contient aucune carte, peut-être pour ne pas retarder encore plus la publication, déjà mise à mal par l'incendie de l'imprimerie Giunti en 1557. 
Si ces cartes sont riches et magnifiques, pour Ramusio il ne peut s'agir que d'une représentation provisoire, amenée à évoluer au gré des nouveaux acquis à venir et de la levée des incertitudes demeurant encore sur certaines zones du monde.

\section{LE DISCORSO D'UN GRAN CAPITANO : PRÉSENTATION DU TEXTE ET DE SES DIFFÉRENTES ÉDITIONS}

\section{Éditions en italien}

Le Discorso d'un gran capitano ${ }^{30}$ a été publié pour la première fois dans le troisième volume des Navigationi et viaggi de Ramusio, paru à Venise chez l'imprimeur Giunti en 1556, fol. 423-434v. C'est cette édition qui a été utilisée ici, grâce à l'exemplaire numérisé conservé à la bibliothèque de Heidelberg ${ }^{31}$. Une seconde édition parut en 1565, dans laquelle le Discorso d'un gran capitano figure au même emplacement ${ }^{32}$. Une troisième édition parut en 1606 ; le Discorso s'y trouve fol. $352-371 \mathrm{v}^{33}$. Une reproduction anastatique, reproduisant la version de 1606 du troisième volume, est parue à la fin des années $1960^{34}$. Enfin, plus récemment, M. Milanesi et la maison Einaudi ont mis à la disposition du public une nouvelle édition ${ }^{35}$.

\section{Éditions en français}

\section{Louis Estancelin (1832)}

Louis Estancelin (1777-1858) était un historien et homme politique normand, qui fut notamment député de la Somme entre 1830 et $1846^{36}$. En 1831, le hasard met entre ses mains un manuscrit intitulé Voyage des Dieppois, relatant les aventures du Sacre et de la Pensée, deux navires commandés par

30 Son titre complet est le suivant : Discorso d'un gran capitano di mare Francese del luoco di Dieppa sopra le nauigationi fatte alla terra nuoua dell'Indie occidentali chiamata la nuoua Francia da gradi .40. fino a gradi .47. sotto il polo artico, \& sopra la terra del Brasil, Guinea, Isola di San Lorenzo, \& quella di Summatra fino alle quali hanno nauigato le caravelle \& naui Francese.

31 Accessible à l'adresse http://digi.ub.uni-heidelberg.de/diglit/ramusio1556bd3/0928/image (C) Heidelberg University Library (CC-BY-SA 3.0).

32 Consultable par exemple à l'adresse https://upload.wikimedia.org/wikipedia/commons/6/63/ Delle_navigationi_et_viaggi__volume_3_-_1565.pdf.

$3 \overline{3}$ Un exemplaire numérisé conservé à la Bibliothèque nationale de France est disponible sur Gallica : https://gallica.bnf.fr/ark:/12148/bpt6k131851r/f789.image.

34 G.B. Ramusio, Navigationi et viaggi, with an introduction by R.A. Skelton and an analysis of the contents by G.B. Parks, Amsterdam, Theatrum Orbis Terrarum, 1967-1970, 3 vol.

35 G.B. Ramusio, Navigationi et viaggi, a cura di M. Milanesi, Turin, Einaudi, 1978-1988, 6 vol. (le Discours se trouve dans le vol. VI). Des éditions en ligne sont disponibles sur les sites liberliber.it et bibliotecaitalina.it.

36 Il publia, entre autres, une Dissertation sur les découvertes faites par les navigateurs dieppois (1826) et une Histoire des comtes d'Eu (1828). 
les frères Jean et Raoul Parmentier pour le compte de l'armateur Jean Ango. Ce récit, rédigé par l'« astrologue $»^{37}$ de la Pensée, Pierre Crignon, décrit avec précision le voyage effectué par ces Dieppois qui parvinrent à l'île de Sumatra en 1529 et rentrèrent l'année suivante avec des épices. Après avoir pris connaissance du manuscrit dans le détail, Estancelin estime qu'il existait déjà un témoignage écrit, non seulement de ce voyage à Sumatra, mais aussi d'autres voyages potentiellement effectués par Jean Parmentier : le Discours d'un grand capitaine, dans le troisième volume du recueil de Ramusio. Aussi, dans son ouvrage intitulé Recherches sur les voyages et les découvertes des navigateurs normands en Afrique, dans les Indes orientales et en Amérique $(1832)^{38}$, il publie consécutivement le texte de Ramusio, dans sa version italienne suivie d'une traduction en français (ou plutôt d'une rétroversion), puis le manuscrit qu'il s'était procuré39. Estancelin ne précise pas qui est l'auteur de la traduction, mais on peut envisager qu'il s'agisse de lui-même. Aucune des quatre cartes contenues dans le Discours d'un grand capitaine n'est reproduite, seule celle représentant Sumatra est citée.

\section{Le général Langlois (1933)}

En 1933, un siècle après celle d'Estancelin, paraît une seconde traduction en français dans l'ouvrage : G.B. Ramusio, Â la découverte de l'Amérique du Nord. Navigations et voyages (XVI siècle) ${ }^{40}$. Mais, comme l'indique le titre, cette traduction est partielle et concerne seulement la première moitié du texte consacrée à l'Amérique, incluant tout de même la partie sur le Brésil ${ }^{41}$. Le frontispice nous apprend que les textes de Ramusio ont été traduits de l'italien par le général Langlois et par « J.-B. Simon ». Du second, on ne sait presque rien, à part qu'il était licencié ès lettres. Dans la brève introduction ${ }^{42}$, non signée mais visiblement rédigée par le général Langlois, il est remercié pour avoir « bien voulu apporter à cette œuvre une aide précieuse par sa connaissance approfondie de la langue italienne et de la langue espagnole. C'est grâce à son érudition que nous avons pu surmonter la plupart des difficultés du

37 L'« astrologue » était l'officier chargé des observations astronomiques. L'expédition en comptait un sur chaque navire ; Pierre Mauclerc était celui du Sacre.

38 Paris, A. Pinard, 1832 ; rééd. Brionne, Montfort, 1973 ; cité désormais Estancelin, suivi de la pagination ; disponible sur Gallica : https://gallica.bnf.fr/ark:/12148/bpt6k104081d.

39 Navigazioni d'un gran capitano... (p. 194-215), Voyage d'un grand navigateur... (p. 216-240) et Journal du voyage de Jean Parmentier, de Dieppe, à l'île de Sumatra, en l'année 1529 (p. 241-312). Voir aussi, dans la partie consacrée aux « Voyages des navigateurs normands », p. 41-45 et 47-49, ainsi que dans la notice sur le « Voyage des Dieppois à Sumatra en 1529 », p. 188-191.

40 Paris, Centre de documentation André Thévet (Collection de textes relatifs aux anciennes civilisations du Mexique et de l'Amérique centrale ; 8), 1933, p. 109-117 ; cité désormais Langlois, suivi de la pagination.

41 Voir p. 117, n. 1 : « La fin de ce “discours” étant relatif à la Guinée et à Sumatra, et n'ayant aucun rapport avec l'histoire de l'Amérique, n'a pas été traduit ».

42 Signalons ici deux erreurs importantes qui y sont contenues : le troisième volume des Navigationi et viaggi n'est pas paru en 1554, mais en 1556, et Ramusio n'est pas mort en 1547, mais en 1557. 
texte ${ }^{43}$. On en sait un peu plus sur le général Pierre Louis Guillaume, dit Louis Langlois (Saint-Germain-en-Laye 1872-Paris 1938). Militaire, il a également été attaché à l'ambassade de France aux États-Unis, et il publie son ouvrage en tant que membre de la Société des Américanistes ${ }^{44}$. Dans son introduction, il met en avant le rôle joué par Jean Genet (1903-1934) ${ }^{45}$, l'initiateur et le directeur de la "Collection de textes relatifs aux anciennes civilisations du Mexique et de l'Amérique centrale » qui accueillit l'ouvrage ${ }^{46}$. Quant à la traduction, elle s'avéra semée d'embûches : « ce qui est certain, c'est que nous avons été arrêtés, parfois, dans notre traduction des précédentes traductions, par certains passages tellement négligés, qu'il nous a été impossible d'en retrouver le sens original. En d'autres endroits, des lambeaux de phrases ont été omis, ou au contraire, plus ou moins répétés ${ }^{47}$. Il semble que les traducteurs ignoraient la publication d'Estancelin. Langlois explique la démarche qui a été suivie : "Nous n'avons pas cherché à faire dans notre traduction œuvre de littérateur. Nous avons suivi le texte le plus près possible, en lui laissant sa saveur et son caractère. Nous l'avons simplement allégé et aéré pour le rendre d'une lecture plus facile. Il nous a paru préférable de lui laisser son aspect de récit de marins, de voyageurs et d'explorateurs du Xvi ${ }^{\mathrm{e}}$ siècle ${ }^{48}$. Logiquement, seules les deux cartes de Gastaldi relatives à l'Amérique ont été reproduites; celle de La Nuova Francia figurant toutefois au milieu de la Relation de Verrazano, qui précède le Discours d'un grand capitaine.

\section{John Nothnagle (1990)}

Plus récemment, en 1990, une nouvelle traduction en français est parue dans l'ouvrage édité par John Nothnagle : Pierre Crignon : poète et navigateur.

43 Langlois, p. II.

44 Il publia également La découverte de l'Amérique par les Normands vers l'an 1000 : deux sagas islandaises (1924) ; "Quelques considérations topographiques et militaires sur les sites étrusques ", Mélanges d'archéologie et d'histoire publiés par l'École française de Rome, XLIV année, 1927, fasc. I-V, p. 91-102 et L'Amérique précolombienne et la conquête européenne (1928).

45 Jean Genet (1903-1934) était un épigraphiste spécialisé dans les civilisations aztèque et maya. Il fut aussi libraire, éditeur et membre de la Société des Américanistes. Voir la biographie d'É. TALADOIRE, « Jean Genet, a Forgotten Mesoamericanist Epigrapher », Maya Decipherment, 28 octobre 2013 (https:// decipherment.wordpress.com/2013/10/28/jean-genet-a-forgotten-mesoamericanist-epigrapher/).

46 « Il a paru à M. Genet qu'il serait de grand intérêt de donner à tous ceux qui s'intéressent à l'histoire américaine, la traduction des relations concernant le Nouveau-Monde » (Langlois, p. I-II). Pourtant, en plus du Discours d'un grand capitaine, seuls huit textes des Navigationi et viaggi ont été traduits ici, dont les récits espagnols de Francisco Vasquez de Coronado et de Fernando de Alarcón, la Relation de Verrazano et le Discours sur la terre ferme des Indes occidentales... de Ramusio. La raison en est donnée dans le dernier paragraphe : «Le présent volume contient le récit des expéditions espagnoles vers le Nouveau-Mexique et celles des Français vers la Nouvelle-France. Dans un autre volume, nous donnerons la traduction des relations concernant le Mexique, la Californie et terres adjacentes ». Celui-ci, comme plusieurs autres qui étaient en préparation, ne semble jamais être paru, le programme éditorial de la collection ayant été brutalement interrompu par le suicide de Jean Genet le 18 décembre 1934.

47 Langlois, p. II.

48 Ibid. 
Euvres en prose et en vers ${ }^{49}$. John T. Nothnagle est professeur émérite de l'université de l'Iowa, spécialiste en littérature française de la Renaissance ${ }^{50}$. Il a souhaité " réunir toute l'œuvre d'un homme dont la vie et la carrière étaient remarquables " ${ }^{51}$ : Pierre Crignon, l'auteur du journal de bord relatant le voyage du Sacre et de la Pensée à Sumatra en 1529-1530, auquel il attribue également le Discours d'un grand capitaine. C'est pourquoi il a publié ensemble ces deux documents, aux côtés des œuvres poétiques de Crignon. Pour la traduction, J. Nothnagle explique qu'il l'a effectuée lui-même ${ }^{52}$. Il mentionne brièvement celle d'Estancelin, en déplorant que son livre soit " presque introuvable ${ }^{53}$, mais il ne la critique pas, et ne dit pas non plus s'il s'en est servi pour son propre travail. Il cite également l'édition anglaise dont il est question juste après, mais il semble ignorer celle de Langlois. Les quatre cartes de Gastaldi sont reproduites.

\section{Édition en anglais (1963)}

En 1963, une édition en anglais est parue dans la revue américaine Ethnohistory par les soins de Bernard G. Hoffman, professeur au département d'anthropologie de l'université du Maryland et spécialiste des Amérindiens ${ }^{54}$. Après une introduction où il déplore que ce document n'ait jamais été correctement traduit en anglais ${ }^{55}$ ou analysé en littérature ethnographique et qu'il est donc resté généralement méconnu, voire inconnu des Américanistes, B.G. Hoffman en présente une traduction en anglais effectuée à partir de la seconde édition de 1565 , avec des notes et des commentaires visant à souligner son importance pour l'ethnohistoire

49 Birmingham, Summa Publications Inc., 1990, p. 95-113 ; cité désormais Nothnagle, suivi de la pagination ; disponible en partie sur GoogleBooks.

50 Il a également traduit et édité Sa vie à ses enfants d'Agrippa d'Aubigné : His Life, to his Children by Theodore-Agrippa d'Aubigné, Lincoln, University of Nebraska Press, 1989 ; il est aussi l'auteur de « Two Early French Voyages to Sumatra », Sixteenth Century Journal, XIX, n 1, 1988, p. 97-109, et de « Les cartographes de l'Amérique du Nord (1520-1763) », dans Les Français des États-Unis d'hier à aujourd'hui, R. Creagh (dir.), Montpellier, Université Paul Valéry - Montpellier III, 1995, p. 25-42.

51 Nothnagle, p. 8.

52 Ibid., p. 4 (« A cause de son intérêt historique j’ai retraduit ce texte en français ») et 8 (« Je me suis permis de le remettre encore en français »).

53 Ibid., p. 8.

54 B.G. Hoffman, « Account of a Voyage Conducted in 1529 to the New World, Africa, Madagascar, and Sumatra, Translated from the Italian, with Notes and Comments », Ethnohistory, vol. 10, $\mathrm{n}^{\circ} 1$, Winter 1963, p. 1-79. Cité désormais Hoffman, suivi de la pagination ; disponible sur http://www.jstor.org/ stable/480388. B.G. Hoffman est également l'auteur, entre autres, de Cabot to Cartier. Sources for a Historical Ethnography of Northeastern North America, 1497-1550, Toronto, University of Toronto Press, 1961.

55 Les éditions en français d'Estancelin et de Langlois n'y sont pas citées. 
américaine ${ }^{56}$. Signalons enfin que la partie consacrée à la Guinée avait déjà été traduite en anglais en $1942^{57}$.

\section{Pourquoi réaliser une nouvelle traduction / édition?}

La traduction d'Estancelin est un travail méritoire, mais elle prend par moments d'assez grandes libertés avec le texte original. De plus, certains passages sont résumés, des mots ou de courtes séquences sont omis, et on relève également quelques erreurs assez importantes et des approximations. Celles de Langlois et de Nothnagle, beaucoup plus proches du texte, sont de meilleure qualité, mais contiennent tout de même des inexactitudes et des imprécisions. En outre, la première n'est que partielle.

Pour établir le texte définitif, ces trois traductions ont été prises en compte et analysées. Nous avons signalé en note les manques ou les erreurs manifestes, et dans certains cas leurs versions sont mentionnées car les choix de traduction peuvent toujours être discutés.

Au-delà de la traduction, nous avons été particulièrement attentifs à l'apparat critique. Dans l'édition d'Estancelin, on ne trouve qu'une seule note, portant sur une polémique avec l'historien espagnol Martin Fernandez de Navarette, qui, dans sa Colección de los viages y descubrimientos, que hicieron por mar los Españoles desde fines del siglo XV (1829), remet en cause la présence précoce des marins et pêcheurs normands, bretons et basques dans les parages de Terre-Neuve. Estancelin a eu le mérite d'effectuer la première traduction en français du Discours d'un grand capitaine et de le mettre en parallèle avec le voyage des Parmentier mais, par exemple, il ne s'est pas préoccupé d'identifier les toponymes rencontrés.

L'édition de Langlois, même si elle ne porte que sur la partie du texte consacrée à l'Amérique, ne comporte que dix notes extrêmement brèves, dont trois qui concernent la datation du texte, et la dernière, déjà citée, qui explique pourquoi la traduction s'arrête à cet endroit.

Celle de Nothnagle contient seulement trente notes assez courtes, mis à part la première, où il donne sa propre traduction de l'extrait du Discours sur la terre ferme des Indes occidentales... qui évoque le Discours d'un grand capitaine et dont il est question juste après. Là encore, il manque notamment

56 Treatise of a great French sea captain from Dieppe on voyages made to the new [found] Land of the West Indies, called New France, situated in 40 to 47 degrees below the North Pole, and on the lands of Brazil, Guinea, Madagascar, and Sumatra which have been reached by French ships and caravels (p. 10-31). Viennent ensuite une reproduction en fac-similé du texte de 1565, sans les quatre cartes (p. 33-40), puis les notes (p. 41-69) et la Bibliographie (p. 69-79). B.G. Hoffman a également publié sa traduction dans New American World, D.B. Quinn (éd.), t. I : America from Concept to Discovery : Early Exploration of North America, New York, Arno Press, 1979, p. 156-157.

57 J.W. Blake, Europeans in West Africa (1450-1560), Londres, The Hakluyt Society, 1942, vol. 1, p. $166-169, \mathrm{n}^{\circ} 63$. 
des informations ou des précisions géographiques. Un compte rendu paru en 1992 sur l'ensemble de l'ouvrage, dont nous partageons l'opinion, pointe particulièrement le manque de critique et d'explications, et même la faiblesse de la langue française ${ }^{58}$.

Enfin, l'édition en anglais de B.G. Hoffman comprend soixante-cinq notes principalement à caractère anthropologique, donnant des descriptions de populations d'Amérique du Nord et du Brésil issues de récits postérieurs pour les comparer à celles du Discours d'un grand capitaine.

Afin d'apporter de nouveaux éléments à la connaissance et à la compréhension du Discours d'un grand capitaine, nous avons souhaité réaliser une nouvelle annotation scientifique, tenant compte des éditions précédentes et comportant différents types de notes : des notes géographiques, historiques, de traduction et de définition. Nous avons souhaité réaliser une édition numérique disponible et accessible pour tous, afin de faire connaître ce texte révélateur des connaissances et de l'expérience acquises par les Normands dans le premier tiers du XVI ${ }^{\text {e }}$ siècle sur des territoires aussi différents que l'Amérique du Nord, le Brésil, la Guinée et Sumatra.

\section{Présentation du texte}

Comment Ramusio s'est-il procuré le Discours d'un grand capitaine? On apprend dans son Discorso sopra il terzo volume, dédié à Girolamo Fracastoro, que ce sont «alcuni Eccellenti buomini Francesi » qui ont envoyé de Paris à son ami humaniste "le relationi della Nuoua Francia " ${ }^{59}$, dont il fait partie avec la Relation de Verrazano et les récits des deux premiers voyages de Cartier. Toutefois, il faut remarquer que, à plusieurs reprises dans son œuvre, Ramusio attribue à Fracastoro ou au cardinal Bembo des correspondants qui sont en fait les siens ${ }^{60}$. Il était donc peut-être lui-même en contact avec ces mystérieux personnages français, dont on aimerait pouvoir percer l'identité et savoir comment eux-mêmes se sont procuré ces quatre textes ${ }^{61}$.

Dans son Discorso sopra la terra ferma... situé peu avant ${ }^{62}$, Ramusio explique brièvement pourquoi il a décidé de traduire et de publier le Discours d'un grand capitaine et en donne une rapide description :

58 Compte rendu réalisé par Janis L. Pallister dans The French Review, vol. 66, n 1, octobre 1992, p. 126-128 (disponible sur https://www.jstor.org/stable/397235?seq=1\#page_scan_tab_contents).

59 Discorso sopra il terzo volume delle navigationi, et viaggi nella parte del mondo nuovo indirizzato, vol. III, 1556 , fol. $5 \mathrm{v}$.

60 D’après F. Lejosne, Giovanni Battista Ramusio..., op. cit.

61 Mais en aucun cas on ne peut suivre Nothnagle, qui tient pour acquis que c'est Pierre Crignon qui les aurait envoyés lui-même à Ramusio : « Les textes que Crignon envoya à Ramusio »; « en 1539, il fournit à Gian-Battista Ramusio un mémoire extrêmement intéressant » ; "Crignon, dans le "discours" qu'il fournit à Ramusio » (Nothnagle, p. 2, 4, et note 7 p. 50).

62 Le Discorso sopra la terra ferma... est situé aux fol. 417-419v. Il est suivi par la relation du premier voyage de Verrazano (fol. 420-422v), puis par le Discours d'un grand capitaine (fol. 423-434v). 
A été ensuite ajouté un écrit, ou nous voulons dire un discours fait en 1539 par un grand capitaine français, que nous avons voulu traduire de sa langue dans la nôtre, où il décrit le voyage qui se fait à la terre neuve des Indes occidentales, qu'on appelle à présent la Nouvelle France, et aussi à la terre du Brésil, qui fait également partie desdites Indes, à la Guinée, à la côte de la Malaguette en Afrique, que tous les jours les Français fréquentent avec leurs navires. Par la suite ce capitaine, avec deux navires armés à Dieppe en Normandie, voulut aller jusqu'à l'île Taprobane, au Levant, à présent nommée Sumatra, où il négocia avec ces peuples et, chargé d'épices, revint chez lui. Ce discours nous a semblé vraiment très beau et digne d'être lu par tous, mais nous sommes vraiment désolés de ne pas connaître le nom de l'auteur, car en n'indiquant pas son nom il nous semble faire injure à la mémoire d'un si vaillant et gentil chevalier ${ }^{63}$.

Le Discours d'un grand capitaine est un document à la fois très riche mais aussi relativement énigmatique et quelque peu obscur. Ramusio lui-même avoue ne pas en connaître l'auteur, qu'il semble assimiler au fameux grand capitaine, mais il s'agit bien de deux personnages distincts. Quant à la datation, si l'extrait ci-dessus indique la date de 1539, nous allons voir que l'ensemble du contenu ne date pas forcément de cette période, et nous essaierons aussi de définir plus précisément le contexte de rédaction. Avant de tenter d'apporter des réponses ou du moins de proposer des hypothèses sur ces points fondamentaux, entrons plus en détail dans le contenu du texte.

Le texte débute par ce qu'Estancelin a appelé une « dissertation hydrographique ${ }^{64}$ où sont longuement définies, sur un ton très personnel, la latitude et la longitude (fol. 423). Il s'agit d'une présentation cosmographique de la Terre, assez basique, une sorte de digeste pour quelqu'un n'ayant pas sous les yeux une représentation du monde. On peut s'interroger, de prime abord, sur l'utilité de cette introduction, qui ne paraît pas indispensable à la compréhension du texte qui suit, dont elle se démarque clairement par sa nature technique.

En effet, comme l'indique pourtant un passage de cette introduction - «Or, pour en venir à notre sujet principal et pour faire la description des terres visitées selon la carte marine ${ }^{65}-$ la suite du texte (fol. 423-429v) présente pour chaque région décrite (côte nord-américaine, Brésil et Guinée ${ }^{66}$ ), non pas un ou des récits de voyages, mais des observations géographiques et ethnologiques. Une sorte de vade-mecum en fait, rythmé par des titres clairs :

63 Pour le texte italien, voir Discorso sopra la terra ferma..., vol. III, 1556, fol. 417v. Les trois éditions françaises précédentes donnent également leur traduction du passage complet : Estancelin p. 190-191, Langlois p. 88-89 et Nothnagle p. 111, n. 1, mais en donnant une localisation erronée : «dans son introduction au troisième volume des Navigationi et Viaggi ». Il indique plus bas « (III, fol. 438) », renvoyant à l'édition de 1606 .

64 Estancelin, p. 190.

65 Hor per venire alla nostra materia suggeta \& per far la descrittione delle terre nauigate secondo la charta marina (fol. 423).

66 On trouve également quelques lignes sur la côte sud-ouest de l'Afrique et sur Madagascar (bas fol. 429 et $429 v)$. 
«Sommaire et brève description de la nouvelle terre, et premièrement de sa situation ", "De la pêche que font les sauvages ", " De ceux qui ont découvert la nouvelle terre », «De la terre de Norumbega », « De la terre du Brésil et de la route pour y aller ", " Des habitants de ladite terre, de leurs vêtements et de leurs armes ", "De leur mode de vie et de leurs coutumes ", "Description de la côte de la Guinée » et « Du voyage qui se fait à la côte de la Guinée ». À l'exception d'un passage critiquant sévèrement les Portugais (fol. 426v), sur lequel nous reviendrons, toute cette partie du texte est rédigée de manière impersonnelle.

À partir du fol. 432, s'opère une transformation majeure. Si cette dernière partie, consacrée à Taprobane / Sumatra, n'est pas clairement annoncée comme les autres par un titre ${ }^{67}$, elle s'en distingue nettement par le ton très personnel qui y est adopté : l'auteur a vécu directement les événements ${ }^{68}$. Sur le plan de la forme, on a l'impression qu'un morceau a été rajouté, même si le contenu se rapproche de celui des autres parties : on y trouve quelques informations géographiques sur Sumatra, mais essentiellement une description des habitants de Ticou, un port situé sur la côte occidentale de l'île. Celle-ci est agrémentée de deux « sous-titres » : "Des armes de ceux de la Taprobane » et «Des fruits de ce pays, et des grains ». Plusieurs passages démontrent sans ambiguité qu'il s'agit bien d'un témoignage sur le voyage du Sacre et de la Pensée, qui séjournèrent à Ticou du $1^{\text {er }}$ au 27 novembre $1529^{69}$, comme l'avait remarqué en premier lieu Estancelin, et après lui les autres éditeurs de ce document ${ }^{70}$.

On trouve donc plusieurs types d'informations dans ce texte qui s'apparente à un état des connaissances sur les différentes contrées décrites. D'abord des indications géographiques relativement précises, une espèce de routier, non pas pour s'y rendre, mais pour se repérer sur place. Ensuite divers éléments sur les populations rencontrées : leurs mœurs, leur degré d'hospitalité et leur plus ou moins grande inclinaison à commercer. Enfin, l'affirmation de la primauté - ou au moins de la présence avérée - des Français dans ces régions récemment découvertes par rapport aux Portugais, qui s’en prétendent

67 Nothnagle a ajouté entre crochets [Du voyage aux Indes orientales] (p. 107).

68 «à mon avis », « Je n'ai eu affaire », « les marchandises que nous avions apportées là », " pour nous autres » (fol. 432), « après avoir chargé nos navires de poivre et d'autres épices, nous retournâmes à Dieppe » (fol. 432v).

69 Les deux navires firent ensuite escale à Selagan, un port situé plus au sud (23-28 décembre), puis, remontant légèrement au nord, à Indrapour (29 décembre-22 janvier 1530).

70 Un demi-siècle après Estancelin, l'historien Pierre MARGRY publia le « Journal d'une navigation des Dieppois dans les mers orientales sous François Ir (1529-1530) », dans le Bulletin de la Société normande de géographie, t. V, 1883, p. 168-184 (mars-avril 1883), 233-248 (juillet-août 1883) et 321-339 (septembre-octobre 1883). La même année, Charles SCHEFER, membre de l'Institut, publia à son tour, d'après un manuscrit différent, Le discours de la navigation de Jean et Raoul Parmentier, de Dieppe, voyage à Sumatra en 1529, Paris, E. Leroux (Recueil de voyages et de documents pour servir à l'histoire de la géographie ; IV), 1883 (rééd. Genève, Slatkine Reprints, 1971). Enfin, comme on l'a déjà évoqué, Nothnagle le publia en 1990 aux côtés du Discours d'un grand capitaine (p. 13-52). 
les premiers découvreurs et par conséquent les seuls habilités à en exploiter les richesses. Remarquons quau contraire, à deux reprises (fol. $423 \mathrm{v}$ et 426 ) les limites des Indes occidentales espagnoles sont clairement indiquées et ainsi reconnues comme légitimes.

L'arrière-fond commercial de ce texte est indéniable et omniprésent. Il peut apparaître au premier abord comme une sorte de guide destiné à des marchands, mais il s'agit avant tout d'un plaidoyer en faveur de la liberté du commerce maritime, entravé par les interdictions d'aller trafiquer en Guinée et au Brésil édictées par François I ${ }^{\text {er. }}$.

\section{NOUVELLE ANALYSE CRITIQUE}

\section{La datation et le contexte de rédaction}

Si ce texte a bel et bien été rédigé en 1539 , cela ne signifie pas pour autant que les informations qu'il contient datent elles aussi de la même période. Examinons les différents éléments de datation disséminés dans le texte.

Dans la partie consacrée à la côte nord-américaine, plusieurs extraits indiquent que la " nouvelle terre " est perçue comme un ensemble, notamment : "La nouvelle terre s'étend vers le pôle arctique du $40^{\mathrm{e}}$ degré jusqu'au $60^{\mathrm{e}} "$ (fol. 423v), alors que l'île de Terre-Neuve s'étend en latitude seulement de $46^{\circ} 37^{\prime}$ à $51^{\circ} 39^{\prime}$ Nord. Citons également, juste après, le passage : « Du Capo di $\operatorname{Ras}^{71}$ jusqu'au cap des Bretons, la côte s'étend de l'Est à l'Ouest sur 100 lieues " (fol. 423v), où l'auteur ne semble pas connaître l'existence du détroit de Cabot, qui sépare Terre-Neuve de l'Île du Cap-Breton. Il paraît ignorer les apports des deux premiers voyages de Jacques Cartier (1534 et 1535-1536), pourtant antérieurs à 1539 , et en particulier l'insularité de Terre-Neuve. Cela pourrait signifier que soit il n'a pas eu connaissance des éléments nouveaux issus des deux premiers voyages du Malouin, ce qui semble improbable, soit que ce passage du texte reprend une description antérieure à 1534 .

On pourrait objecter que le récit du premier voyage de Cartier contient certains traits communs avec le Discours d'un grand capitaine, comme par exemple le terme " margaux " (les fous de Bassan), le toponyme "entrée ou golfe des châteaux » (le détroit de Belle-Isle), ou encore la description des Indiens avec notamment leurs barques faites d'écorce de bouleau ${ }^{72}$. Mais quoi de plus

71 Le cap Race, au sud-est de Terre-Neuve.

72 Même si l'auteur du Discours d'un grand capitaine distingue deux peuples à deux endroits différents, on peut rapprocher ses descriptions de celle effectuée par Cartier en juin 1534 alors qu'il se trouve sur la côte du Labrador à l'ouest de la baie du Vieux Fort : « Il y a des gens à ladite terre qui sont assez de belle corpulance mais ilz sont gens effarables et sauvaiges. Ilz ont leurs cheveulx liez sur leurs testes en faczon d'une pongnye de fain [foin] teurczé et ung clou passé par my ou aultre chosse et y 
logique puisque Cartier - qui n'est pas cité au contraire de Verrazano - parcourt les mêmes régions que celles décrites par l'auteur du Discours d'un grand capitaine. Et surtout, ces éléments peuvent tout autant provenir de n'importe quel voyage à Terre-Neuve, fréquentée depuis plusieurs décennies par les marins français, voire de récits portugais connus en France, tel celui du second voyage de Gaspar Corte-Real en $1501^{73}$.

Un autre argument allant dans le sens d'une datation avant 1534 est la distinction opérée entre les Français et les Bretons (fol. 423v), reprise plus loin dans la partie sur le Brésil (fol. 426). On en trouve une également entre les Normands et les Bretons, à deux reprises (fol. 423v). Le duché de Bretagne ayant été officiellement rattaché à la Couronne en 1532, ces différents passages pourraient s'avérer antérieurs à cette date.

La partie « De ceux qui ont découvert la nouvelle terre » (fol. 423v) contient quelques éléments de datation. Si la date de 1508 est indiquée pour le voyage du Dieppois Thomas Aubert, c'est certainement à partir de ce passage que de nombreux auteurs anciens ont attribué aux Bretons et aux Normands des voyages à Terre-Neuve dès 1504 , et notamment celui du Honfleurais Jean Denis en $1506^{74}$. En effet, ces dates peuvent facilement être déduites en prenant pour base la datation du texte en 1539 et en tenant compte des éléments que l'on y trouve (« il y a 35 ans » et « Cela fait environ 33 ans »). Pourtant, il est évident que l'on ne peut ni dater ni identifier avec précision les premiers voyages français sur les côtes nord-américaines. Comme leurs homologues anglais et portugais, les marins français les fréquentaient depuis plus ou moins longtemps pour la pêche à la morue ${ }^{75}$. Ces expéditions ne laissaient pas de traces documentaires et tous cherchaient à conserver le secret de leurs navigations afin de ne pas renseigner leurs concurrents de plus en plus nombreux et

lient aulcunes plumes de ouaiseaulx. Ilz se voistent de peaulx de bestes tant hommes que femmes mais les femmes sont plus closes et serrees en leursdites peaux et sçaintes par le corps. Ilz se paingnent de certaines couleurs tannees. Ilz ont des barques en quoy ilz vont par la mer qui sont faictes d'escorche de bouays de boul o quoy ilz peschent force loups marins. Dempuis les avoir veuz j'ay seu que là n'est pas leur demeurance et qu'ilz viennent des terres plus chauldes pour prandre desditz loups marins et autres choses pour leur vie » (J. CARTier, Relations, M. Bideaux (éd.), Montréal, Presses de l'université de Montréal, 1986, p. 101).

73 L'une des lettres qui donne des informations sur ce voyage, rédigée par l'ambassadeur de Venise à Lisbonne Pietro Pasqualigo, avait été publiée dans les Paesi novamente retrovati... de Montalboddo, recueil traduit en français dès 1515 par Mathurin du Redouer sous le titre S'ensuyt le Nouveau monde...

74 U. Chauveton, Brief discours et histoire d'un voyage de quelques François en la Floride (1579), p. 35 ; repris par La Popelinière, Les trois mondes (1582), liv. II, art. 11, p. 46 ; C. VAN WytFliet et A. Magin, Histoire universelle des Indes occidentales et orientales et de la conversion des Indiens (1611), liv. 1, chap. 1, p. 96 ; Père P. Biard, Relation de la Nouvelle France (1616), p. 2-3 ; P. Bergeron, Traicté de la navigation et des voyages de descouverte \& Conqueste modernes, \& principalement des François (1629), p. 100-101 ; Père G. FourniER, Hydrographie (1643), p. 319 ; J. SAVARY, Le parfait négociant (1675), livre second, p. 114 ; Père P.F.X. DE Charlevoix, Histoire et description générale de la Nouvelle France (1744), t. I, p. 3-4.

75 Voir R. Litalien, Les explorateurs de l'Amérique du Nord, 1492-1795, Sillery, Les éditions du Septentrion, 1993, p. 61-65: «Les pêcheurs de morues, explorateurs anonymes ». 
actifs. En France, les Normands (de Dieppe, Honfleur, Le Havre), les Bretons et les Basques ${ }^{76}$ revendiquent chacun la primauté de la présence sur ces côtes sans preuve décisive et, sauf découverte improbable de nouveaux documents, « il est probable que la question de la date des débuts de l'exploitation des bancs de morue de Terre-Neuve ne sera jamais entièrement résolue $»^{77}$.

Si les Anglais et les Portugais peuvent mettre en avant les explorations officielles effectuées par Jean Cabot / Giovanni Caboto en 1497-1498 et par les frères Corte-Real entre 1500 et $1502^{78}$, nous ne disposons de rien de tel en France. Même s'ils ont été sans aucun doute précédés par d'autres, les premiers voyages normands et bretons attestés datent de $1508^{79}$ et de $1510^{80}$, et on sait que Rouen représentait déjà à cette période pour la vente des morues un marché central, en relation avec toutes les grandes places européennes et avec l'énorme marché parisien ${ }^{81}$.

Le Discours d'un grand capitaine est la seule source contemporaine qui mentionne les voyages de Jean Denis et de Thomas Aubert. Ces expéditions étaient-elles menées pour la pêche ou bien avec un objectif de découvertes? Jean Denis, accompagné d'un pilote rouennais nommé Camart, aurait été le premier, vers 1506, à parvenir dans la région du détroit de Belle-Isle (le " golfe des châteaux »), qui sépare Terre-Neuve et le Labrador, constituant

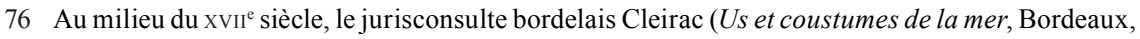
1647, p. 151) prétendait que les Basques, plutôt que les Dieppois, auraient découvert, un siècle avant Colomb, Terre-Neuve et la Nouvelle-France. Voir N. LANDRY, « Les Basques dans le golfe du Saint-Laurent se racontent ", Acadiensis. Journal of the history of the Atlantic Region / Revue d'histoire de la région atlantique, vol. XXXVII, n² 2, été-automne 2008 : https://journals.lib.unb.ca/index.php/acadiensis/article/ view/11153/11880\#no1.

77 F. BRumont, « Les Normands à Terre-Neuve au XVI siècle », Annales de Normandie, $68^{\mathrm{e}}$ année, $\mathrm{n}^{\circ} 2$, juillet-décembre 2018, p. 36 .

78 Voir notamment les deux ouvrages de H. HARrisse : Jean et Sébastien Cabot, leur origine et leurs voyages et Les Corte-Real et leurs voyages au Nouveau Monde, Paris, Leroux (Recueil de voyages et de documents pour servir à l'histoire de la géographie depuis le XIII jusqu'a la fin du XVI ${ }^{e}$ siècle ; I, III et III bis), 1882 et 1883, ainsi que E. BRAZÃo, "Les Corte-Real et le Nouveau-Monde », Revue d'histoire de l'Amérique française, vol. 19, n 1, juin 1965, p. 3-51; n², septembre 1965, p. 163-202; n 3, décembre 1965, p. 335-349, et, dans ce dernier numéro, la contribution de L. CAMPEAU, « Jean Cabot et la découverte de l'Amérique du Nord », p. 384-413.

79 Voir Documents authentiques et inédits pour servir à l'histoire de la marine normande et du commerce rouennais pendant les XVI et XVII siècles, É. GossELIN (éd.), Rouen, Boissel, 1876, p. 12-13, où sont cités, " à dater de 1508 », plusieurs noms de navires, de capitaines et de bourgeois. La plus ancienne mention documentaire d'un armement normand pour Terre-Neuve est datée du 21 octobre 1508. Il s'agit d'une pièce de procès relative à un voyage antérieur, celui de La Bonne Avanture, publiée par M. Mollat, «Choix de documents relatifs à la Normandie pour servir à l'histoire du commerce maritime $\left(\mathrm{XV}^{\mathrm{e}}-\mathrm{XVI}^{\mathrm{e}}\right.$ siècles) "), Mélanges de la Société de l'histoire de Normandie, 16 ${ }^{\mathrm{e}}$ série, 1959, p. 152-154 (réimp. dans Études d'histoire maritime, Turin, Bottega d'Erasmo, 1977, p. 202-204).

80 En septembre 1510, la Jacquette de Pléneuf (Côtes-d'Armor) est venue vendre à Rouen « du poysson qu'ilz avoient esté quérir et pescher és parties de la Terre-Neusfve ». Document publié par H.P. Biggar, Les précurseurs de Jacques Cartier, 1497-1534. Collection de documents relatifs à l'histoire primitive du Canada, Ottawa, Imprimerie de l'État, 1913, n XXXV, p. 116-118, et avant lui par A. DE LA Borderie dans les Mélanges d'histoire et d'archéologie bretonnes, t. II, 1858, p. 153-156 puis dans « Les Bretons à Terre-Neuve en 1510 », Annales de Bretagne, t. IX, n 1, novembre 1893, p. 435-437.

81 Voir M. Mollat, Le commerce maritime normand à la fin du Moyen Âge : étude d'histoire économique et sociale, Paris, Plon, 1952, p. 262-263. 
le débouché septentrional du golfe du Saint-Laurent. Il aurait également découvert une partie du Brésil vers $1519^{82}$. Qui est ce mystérieux capitaine honfleurais ? Il pourrait s'agir d'un des deux Jehan Denys (l'aîné et le jeune) figurant sur un registre de la confrérie de charité de la paroisse Notre-Dame de Honfleur, notamment en 1482 et en 1497, où il est cité parmi d'autres bourgeois de Honfleur dans une délibération du 17 mai 1502 153 . Un Jehan Denis propriétaire d'un navire « de Honnefleu » revenant richement chargé de Messine et de Naples est également signalé en $1492^{84}$. Une carte de l'embouchure du Saint-Laurent lui a été parfois attribuée mais c'est un document apocryphe ${ }^{85}$. En revanche, dans un manuel de navigation daté vers 1540-1545 est mentionné un « havre de Jehan Denys, dict Rongnoust " ${ }^{86}$ où sont laissées des embarcations entre deux saisons de pêche. Ce toponyme correspondant aujourd'hui à Renews Harbour, sur la côte orientale de Terre-Neuve (à environ $18 \mathrm{~km}$ au nord du cap Race), est revendiqué par les Basques ${ }^{87}$. Jacques Cartier y passa avant de prendre la route du retour lors de son second voyage en juin 1536 mais ne semble le connaître que sous le nom de "Rougnouse »"

Jean Denis aurait été suivi, en 1508, par Thomas Aubert (dont une avenue porte le nom à Montréal), à bord de la Pensée appartenant à Jean Ango père. D'après une source du XVIII ${ }^{\mathrm{e}}$ siècle, «le Pilote Aubert » aurait été au service du cardinal Georges d'Amboise (archevêque de Rouen et principal ministre de Louis XII à partir de 1498), pour le compte duquel il aurait commandé deux navires avec l'objectif de fonder un établissement au Nouveau Monde. Face à la puissance des Espagnols déjà solidement installés dans « une bonne partie de l'Amérique Méridionale », il aurait mis le cap au Nord et, naviguant pendant «trois ou quatre ans », il aurait découvert « une partie de l'Amérique Septentrionale » sans toutefois être en mesure de remplir sa mission à cause de l'hostilité des indigènes ${ }^{89}$. S'agit-il d'une légende, à l'instar de celle du Dieppois Jean Cousin, prétendu découvreur du Brésil et du cap de Bonne-Espérance ?

82 Voir infra.

83 Documents relatifs à la marine normande et à ses armements aux XVI et XVII siècles pour le Canada, l'Afrique, les Antilles, le Brésil et les Indes, C. et P. BrÉArd (éd.), Rouen, Lestringant, 1889, p. 42-45.

84 A. Spont, «La marine française sous le règne de Charles VIII », Revue des questions historiques, $28^{\mathrm{e}}$ année, nouvelle série, t. XI, 1894, p. 427, d'après BnF, ms. fr. 15540, fol. 132.

85 Père P. Biard, Relation de la Nouvelle France, p. 3 ; Père P.F.X. De Charlevoix, Histoire et description générale de la Nouvelle France, t. I, p. 4 ; abbé A. AnTHIAume, Cartes marines, constructions navales et voyages de découvertes chez les Normands 1500-1650, Paris, Dumont, 1916, t. I, p. 155-156.

86 Regyme pour congnoistre la latitude de la region et aussi la haulteur de la ligne equinotialle sur nostre orison (BnF, ms. fr. 24269, fol. 55). Ce document est connu surtout des africanistes car il contient un « langaige de Guinée », ainsi qu'un « langaige du Bresil », étudiés par D. Dalby et P. Hair en 1964 et 1966.

87 Voir abbé A. Anthiaume, Cartes marines..., op. cit., t. I, p. 157-158 ; M. Mollat, La vie quotidienne des gens de mer en Atlantique, IX $X^{e}-X V I^{e}$ siècle, Paris, Hachette, 1983, p. 191.

88 «Et vynmes au cap de Raze et entrames dedans ung hable nommé Rougnouse où prynsmes eaues et boys pour traverser la mer et là laissames l'une de noz barques » (J. Cartier, Relations, p. 184).

89 L. LEGENDRE, Vie du cardinal d'Amboise, premier ministre de Louis XII, Rouen, Robert Machuel, 1724, p. 371-372. 
On peut plutôt attribuer avec moins d'incertitude à Thomas Aubert le fait d'avoir ramené plusieurs indigènes nord-américains en Normandie en 1509 comme il était de "coutume $»^{90}$ afin de prouver la véracité de ses découvertes, mais en aucun cas d'avoir fondé la première colonie française à Terre-Neuve comme le prétendit Estancelin en $1832^{91}$. Il a peut-être été le premier Français à le faire, mais non le premier Européen, devancé en cela par des Portugais et des Anglais. La description de sept captifs de «Terra Novi » amenés à Rouen en 1509 qui se trouve dans le Chronicon d'Eusèbe de Césarée, imprimé par Henri Estienne en $1512^{92}$, correspond-elle aux « gens du dit pays » rapportés par Thomas Aubert? Rien n'est moins sûr, tant l'anecdote des « sept hommes sauvages » de 1509 a donné lieu à de multiples interprétations, variantes, confusions et amalgames ${ }^{93}$.

Enfin, l'auteur du Discours d'un grand capitaine indique que la « terre de Norumbega » a été « découverte il y a 15 ans par messire Jean de Verrazzane ». Au service de François Ir , l'explorateur d'origine florentine Giovanni Verrazano, accompagné de son frère Girolamo, qui était pilote et cartographe, a effectivement reconnu la côte orientale des actuels États-Unis (de la Caroline du Sud au Maine) au printemps 1524, ce qui place forcément ce passage après cette date et correspond avec l'année 1539 donnée plus haut comme date de rédaction du texte. Le terme Orombega apparait pour la première fois en 1529 sur la célèbre mappemonde réalisée par Girolamo, où il désigne une localité parmi d'autres. Il lui a été attribué parfois une origine viking ${ }^{94}$ mais il serait plutôt dérivé d'un mot abénaqui (un peuple amérindien) signifiant une étendue d'eau calme entre deux rapides d'une rivière. Ce toponyme, avec une orthographe variable (Norembergue pour Cartier, Norembègue, Norimbegga, etc.), connut une grande fortune au $\mathrm{XVI}^{\mathrm{e}}$ siècle en devenant une ville, une rivière et / ou un pays mythique et paradisiaque, décrit notamment par Jean Alfonse de Saintonge dans sa Cosmographie (1544) et par André Thevet dans sa Cosmographie universelle (1575). On le trouve par exemple sur la mappemonde de Mercator (1569) ainsi que sur la carte de l'Amérique contenue dans le célèbre Theatrum Orbis Terrarum d'Abraham Ortelius (1570). Cette contrée imaginaire, située quelque part sur la

90 En 1503, Binot Paulmier de Gonneville explique qu'il est « coutume à ceux qui parviennent à nouvelles terres des Indes, d'en amener à Chrétienneté aucuns Indiens » (Le voyage de Gonneville (1503-1505) et la découverte de la Normandie par les Indiens du Brésil, L. Perronne-MoIsés (éd.), Paris, Chandeigne, 1995, p. 24).

91 Estancelin, p. 43.

92 Eusebius, Eusebii Caesariesis Episcopi Chronicon, Paris, 1512, fol. 172v.

93 Voir la mise au point récente de V. MASsE, «Les "sept hommes sauvages" de 1509 : fortune éditoriale de la première séquelle imprimée des contacts franco-amérindiens », dans Éditer la NouvelleFrance, A. Мотsch, G. Holtz (éd.), Québec, Presses de l'université Laval, 2011, p. 83-106.

94 Voir E. Beauvois, La Norambègue : découverte d'une quatrième colonie précolombienne dans le nouveau monde: avec des preuves de son origine scandinave fournies par la langue, les institutions et les croyances des indigènes de l'Acadie (Nouvelle-Écosse, Nouveau-Brunswick et État du Maine), Bruxelles, F. Hayez, 1880. Plus récemment, voir American Beginnings: exploration, culture, and cartography in the land of Norumbega, E.W. BAKer et al. (éd.), Lincoln - Londres, The University of Nebraska Press, 1994. 
côte nord-est des États-Unis, était encore recherchée par Champlain en 1604. Le Discours d'un grand capitaine affirme qu'elle tient son nom " Nurumbega » de ses habitants, qu'elle s'étend « du cap des Bretons [...] jusqu'à la terre de la Floride ", et précise que " Cette terre est nommée par beaucoup la Française [la Francese], et pareillement par les Portugais eux-mêmes » (fol. 423v). Il s'agit ici d'une autre référence à la Relation de Verrazano, qui avait nommé Francesca l'ensemble de la terre qu'il venait de découvriri ${ }^{95}$. Les frères Verrazzano avaient forcément un lien avec Dieppe, puisque c'est dans ce port qu'ils rentrèrent de leur exploration. L'auteur du Discours d'un grand capitaine a donc pu les y rencontrer, ou au moins se trouver aux premières loges pour recueillir des renseignements, même si sa description s'avère sommaire et ne peut être datée précisément. Mais il a pu aussi être en contact avec eux dans les années suivantes. En effet, les deux frères gravitaient forcément dans le milieu du commerce maritime et bancaire normand, puisque leurs expéditions étaient financées en partie par des marchands rouennais, notamment par des compatriotes établis de longue date à Rouen comme la puissante famille Rucellai, mais aussi par Jean Ango par exemple. Ils ont donc pu être en mesure de relater à l'auteur leurs deux premiers voyages, qui les ont conduits sur la côte orientale des États-Unis en 1524 puis sur les côtes du Brésil en 1526-1527. Si Giovanni mourut lors du troisième, sans doute aux Antilles en 1528, Girolamo parvint à rentrer, et il effectua même sans doute un quatrième voyage, qui le mena à nouveau au Brésil en 1529-1530. Éminent pilote, cosmographe et cartographe ayant une expérience directe et se trouvant en lien avec la Normandie, celuici a tout à fait pu se trouver en rapport étroit avec l'auteur et lui fournir une partie des données contenues dans le Discours d'un grand capitaine, au moins en ce qui concerne l'Amérique du Nord et le Brésil. Dans l'état actuel des connaissances, il ne semble pas qu'il ait parcouru les côtes africaines, et il rentra en Toscane à une date inconnue ${ }^{96}$.

Dans la partie consacrée à la Guinée figurent seulement deux brèves évocations d'une présence française qui semble épisodique (fol. 429), mais aucun élément de datation. Même si les Français ont certainement fréquenté ces côtes auparavant ${ }^{97}$, le premier contact commercial connu date de 1503 , lorsque Binot Paulmier de Gonneville fait escale durant dix jours « à la grande terre

95 Notons toutefois que ce passage ne figure pas dans la version, incomplète, publiée par Ramusio juste avant le Discours d'un grand capitaine. Il apparaît seulement dans le manuscrit Cèllere déjà cité, considéré comme le meilleur et le plus complet, mais qui ne fut découvert qu'en 1909. Voir J. HABERT, M. Mollat du Jourdin, Giovanni et Girolamo Verrazano..., op. cit., en particulier p. 4-6, 22-23 et 160. Sur sa mappemonde de 1529, Girolamo nomma toute cette terre non pas Francesca, mais Nova Gallia, c'est-à-dire Nouvelle-France, dénomination destinée à perdurer jusqu'au traité de Paris en 1763. Sous le toponyme Nova Gallia écrit en gros caractères, Girolamo propose aussi Verrazana, sive nova gallia.

96 Girolamo était encore vivant au moins en octobre 1537, lorsqu'il relatait à un cercle d'humanistes florentins la mort de son frère, dévoré par les cannibales. Voir J. HABERT, M. Mollat, Giovanni et Girolamo Verrazano..., op. cit., p. 124.

97 Voir C. Maneuvrier, « De Honfleur au Cap-Vert. Retour sur le voyage de Georges Bissipat dit "le Grec" de 1483 », Annales de Normandie, 68e année, n 1, janvier-juin 2018, p. 45-54. 
dudit cap de Vert, pays à Maures ", où les habitants « troquèrent avec ceux de la navire, du couchou, manière de riz, des poules noires, et autres victuailles, pour fer, rassades, et telles babioles ${ }^{98}$. Le capitaine honfleurais disposait donc des connaissances suffisantes pour savoir où se ravitailler. Rien dans le récit ne montre l'étonnement des marins devant la découverte des côtes de Guinée. $\mathrm{Au}$ contraire, tout semble indiquer qu'il s'agit alors, pour les navires normands effectuant depuis peu la traversée vers le Brésil, d'une étape habituelle et d'une route déjà balisée. On sait que dans les années 1530 les Normands en particulier armaient régulièrement des navires pour la Guinée $e^{99}$. Cependant, ces entreprises étaient clandestines car les Portugais entendaient interdire l'accès de ces côtes à leurs concurrents. Elles ont donc laissé peu de traces, même si elles furent probablement bien plus nombreuses que ce que la documentation nous permet de connaître.

Dans la dernière partie consacrée à Taprobane / Sumatra, le parallèle effectué avec le récit du voyage des frères Parmentier permet de la dater, puisque le Sacre et la Pensée ont séjourné à Ticou en novembre 1529, avant de rentrer à Dieppe l'année suivante. Peu avant cette expédition, des sources indiennes et surtout portugaises signalent la présence d'autres navires normands dans l'océan Indien. Lors du second voyage de Verrazano en 1526, à la suite d'une tempête, l'un des navires, la Barque de Fécamp, parvint à Sumatra, puis s'échoua à Madagascar. Douze survivants parvinrent en juillet 1528 à Mozambique, où ils furent capturés par les Portugais ${ }^{100}$. Une expédition serait partie de Normandie vers les Indes orientales en 1526 ou 1527. Elle comprenait la Marie de bon secours, qui atteignit la côte occidentale de l'Inde, ainsi que deux autres navires, dont l'un fit naufrage à Sumatra tandis que l'autre aurait abordé à Madagascar ${ }^{101}$.

C'est la partie sur le Brésil (fol. 426-426v) qui apporte le plus d'éléments sur la datation. L'auteur y évoque d'abord "l'entrée du détroit dit de Magellan » (fol. 426), localisée très précisément à $52^{\circ} \mathrm{Sud}$, comme cela figure dans le célèbre

98 Le voyage de Gonneville..., op. cit., p. 18. Voir C. Maneuvrier, « Paulmier de Gonneville et le Portugal : un navigateur normand dans la première mondialisation », Revista de História da Sociedade e da Cultura, vol. 16, 2016, p. 95-109.

99 Voir infra.

100 Voir J. Habert, M. Mollat, Giovanni et Girolamo Verrazano..., op. cit., p. 99-115.

101 Voir M. Mollat, "Passages français dans l'océan Indien au temps de François I ${ }^{\mathrm{er}}$ », dans Océan Indien et Méditerranée (6 ${ }^{\mathrm{e}}$ colloque international d'histoire maritime, Lourenço Marquès, 1962), M. Mollat (éd.), Paris, SEVPEN, 1964, p. 239-250 ; P. Haudrère, « Premiers voyages français dans l'océan Indien au XVI ${ }^{\mathrm{e}}$ siècle », dans La France et la mer au siècle des Grandes Découvertes, P. MAsson, M. Vergé-Franceschi (dir.), Paris, Tallandier, 1993, p. 228-238 ; C. DE La Roncière, Histoire de la marine française, t. III, Paris, Plon, 1906, p. 268-269 : A. et G. Grandidier, Collection des ouvrages anciens concernant Madagascar, t. I, Paris, Comité de Madagascar, 1903, p. 59-60 et 86; L. Vitet, Histoire de Dieppe, Paris, Delahays, 1847, p. 258-259 ; P. CHAPELIN, « L’ingénieur, le roi et les satrapes. Georges de Virgile, de Saint-Étienne à l'Empire du Moghol », Bulletin du vieux Saint-Étienne, n 171, 1993, p. 3-26. 
récit de Pigafetta ${ }^{102}$. La Victoria étant revenue à Sanlúcar de Barrameda le 6 septembre 1522, ce passage date, au minimum, des semaines suivantes. Mais l'auteur a également pu trouver cette information dans la traduction française du récit, publiée en 1525 par Simon de Colines sous le titre Le voyage et navigation faict par les Espaignolz es Isles de Mollucques.

Juste après, l'auteur mentionne le rio de la plata (littéralement « le fleuve de l'argent »). L'estuaire fut initialement nommé Rio de Solis en l'honneur de son découvreur officiel João Dias de Solis (sans doute lui-même précédé par d'autres explorateurs), en 1516. Il semble que la dénomination " Rio de la Plata » apparaisse pour la première fois lors du voyage de Sébastien Cabot (au service de Charles Quint) en 1526-1530, en même temps que la présence d'argent, d'où son nom. Dans la cartographie, la première mention connue se trouve sur la carte catalane du Havre de $1534^{103}$.

Ensuite, on trouve : "Cette terre du Brésil fut d'abord découverte par les Portugais, pour certaines parties, il y a environ trente-cinq ans » (fol. 426v). Si l'on considère qu'il est ici fait référence à l'expédition de Pedro Álvares Cabral qui aborda au Brésil en 1500, cela signifierait que ce passage du texte daterait d'environ 1535, et peut-être même avant. Un autre élément qui irait dans ce sens est le passage signalant à Pernambouc (l'actuelle ville de Recife) seulement un minuscule fortin (fol. 426). Or, on sait que la construction de la forteresse de Pernambouc n'a été décidée qu'en 1535, afin de solidifier l'emprise portugaise dans la capitainerie nouvellement fondée ${ }^{104}$, ce qui n'empêche pas la présence préalable de "quelques petits forts de bois" (fol. 426). Toutefois, on pourrait aussi envisager que "il y a environ [circa] trente-cinq ans " soit tout simplement une imprécision de l'auteur ${ }^{105}$, qui n'aurait pas été corrigée par Ramusio, alors que pourtant celui-ci publia dans son premier volume la relation du voyage de Cabral. À moins qu'il ne soit pas fait référence à cette célèbre expédition, mais à d'autres découvertes portugaises dans d'autres secteurs du Brésil, qui elles pourraient avoir eu lieu vers 1504 ? Signalons également que l'idée de la date de 1504 pour la découverte du Brésil n'était pas rare au XVI ${ }^{\mathrm{e}}$ siècle $^{106}$. Par exemple, la carte de l'Amérique d'Abraham Ortelius présente en 1570 une légende «Bresilia a Lusitanis $A^{\circ} 1504$ inuenta».

102 Voir Le voyage de Magellan (1519-1522). La relation d'Antonio Pigafetta et autres témoignages, X. De Castro, J. Hamon, L.F. Thomaz (éd.), Paris, Chandeigne, 2007, t. I, p. 105.

103 Ibid., p. 352-353.

104 G. Medeiros, «Les Portugais face aux Français dans la conquête des capitaineries de Pernambouc et d'Itamarcá au XVI ${ }^{\mathrm{e}}$ siècle ", dans La France et le monde luso-brésilien : échanges et représentations, $X V I^{e}-X V I I I^{e}$ siècles, S. NeIVA (dir.), Clermont-Ferrand, Presses universitaires Blaise Pascal, 2005, p. 74.

105 Nous ne suivons pas l'opinion d'Hoffman (p. 62, n. 45), selon lequel il s'agit d'une confusion de l'auteur, qui aurait à l'esprit le voyage de Binot Paulmier de Gonneville, pourtant cité nulle part dans le document.

106 Voir O. OKuneva, « Essai sur la carte de G. Gastaldi "Brasil” insérée dans "Delle navigationi et Viaggi” de G.B. Ramusio (1556; $1565 ; 1606)$ », Terra Brasilis (Nova Série), 2, 2013, n. 16 (https:// journals.openedition.org/terrabrasilis/743\#toctoln4). 
Avant d'examiner d'autres éléments du texte relatif au Brésil pouvant alimenter notre réflexion, il est nécessaire de préciser le contexte ${ }^{107}$. Depuis le début du $\mathrm{XVI}^{\mathrm{e}}$ siècle, les marins portugais et français, et en particulier normands, se livraient une lutte acharnée pour le lucratif commerce sur les côtes du Brésil (et de la Guinée). Les Portugais avaient pour arguments les bulles pontificales et les accords avec la Castille de la fin du siècle précédent ${ }^{108}$. En tant que premiers découvreurs, ils se prétendaient les seuls habilités à commercer dans ces régions et entendaient en exclure totalement les autres prétendants. Les Français, et surtout les Normands, s'opposaient fermement à ces arguments et les premières décennies $\mathrm{du} \mathrm{XVI}^{\mathrm{e}}$ siècle sont marquées par un nombre incalculable de plaintes des deux parties, avec force captures de navires et massacres d'équipages (avec des tortures plus ou moins raffinées), et également par des lettres de marques délivrées aux armateurs normands comme Jean Ango afin de se payer directement sur les navires portugais des déprédations subies. Ainsi, en 1530, le roi du Portugal estimait à 300 le nombre de ses navires capturés par les Français depuis le début du XVI ${ }^{\mathrm{e}}$ siècle $^{109}$. Malgré l'alliance officielle des deux souverains, leurs marins se livraient une «guerre sourde $»^{110}$, se rendant coup pour coup en vertu du « sempiternel droit de représailles $»^{111}$.

Après avoir indiqué que les Portugais ne sont établis qu’à Pernambouc, l'auteur précise que l'endroit le plus fréquenté par les Français et les Bretons qui viennent se procurer le bois-brésil se situe entre le cap de Saint-Augustin et le río São Francisco, c'est-à-dire environ la côte de l'État de l'Alagoas actuel, au sud de Recife. Il décrit des indigènes libres, assujettis à aucun roi. Il met en avant à plusieurs reprises leur accueil, beaucoup plus amical et favorable aux Français qu'aux Portugais, et décrit le troc qu'ils pratiquent de manière habituelle avec les premiers nommés. D'après lui, les Français - et en l'occurrence les Normands - ont découvert une partie du Brésil, toujours par l'intermédiaire du Honfleurais Jean Denis, celui-là même qui aurait découvert Terre-Neuve ${ }^{112}$, « il y a vingt ans de cela » (fol. 426v). On serait donc tenté de placer cette " découverte » vers 1519, une date qui paraît tardive. Cela

107 Voir C. DE La Roncière, Histoire de la marine française, op. cit., t. III, p. 290-297 (en part. p. 292 et 297) ; M. Mollat, Le commerce maritime normand..., op. cit., p. 249-262, 466-468 et 473-474 (en part. p. 261-262) ; E. GuÉNIn, Ango et ses pilotes, Paris, Imprimerie nationale, 1901, p. 187-242 : « Relations diplomatiques de la France et du Portugal au sujet des prises en mer dans la première partie du XVI ${ }^{\mathrm{e}}$ siècle ».

108 Principalement la bulle Romanus pontifex du pape Nicolas V (1455), le traité d'Alcáçovas (1479), la bulle Inter cotera d'Alexandre VI (4 mai 1493) et le traité de Tordesillas (1494).

109 Lettre de Jean III à son ambassadeur en France, João de Silveira, 26 janvier 1530, citée par E. GuÉnin, Ango et ses pilotes, op. cit., p. 193, d'après Torre do Tombo, Gav. 11, maç. 8, n. 20.

110 C. DE La Roncière, Histoire de la marine française, op. cit., t. III, p. 278.

111 M. Augeron, P. HrodĚJ, « Entre course, contrebande et piraterie, la conquête des mers lointaines au $\mathrm{XVI}^{\mathrm{e}}$ siècle ", dans Histoire des pirates et des corsaires. De l'Antiquité à nos jours, G. Buti, P. HrODĚJ (dir.), Paris, CNRS, 2016, p. 152.

112 Voir supra. 
pourrait s'expliquer tout simplement par le fait que les Européens ne percevaient évidemment pas le Brésil comme un ensemble, au sens géographique où on l'entend aujourd'hui. Ils distinguaient de nombreux secteurs différents, étalés sur des milliers de kilomètres de côtes. Si Cabral a officiellement pris possession du Brésil en 1500 au nom du roi du Portugal, il avait été lui-même précédé par d'autres qui ont également laissé leur nom dans l'histoire (Vicente Yáñez Pinzón, Diego de Lepe, Vespucci...), mais aussi certainement par de nombreux anonymes - portugais, espagnols, français ou autres - venant commercer en divers points du littoral. Toutefois, il ne s'agit pas ici de rouvrir un débat stérile sur l'attribution des premiers contacts européens avec les Amérindiens du Brésil.

D'après une source postérieure d'un demi-siècle, le jésuite espagnol José de Anchieta, les Français auraient abordé pour la première fois au Brésil en 1504, dans la baie de Tous les Saints, et ils auraient remonté le fleuve Paraguaçu ${ }^{113}$. La même année, Gonneville et son équipage, après avoir été malmenés par les tempêtes, ne sont pas en mesure d'estimer précisément leur position, mais se savent tout de même dans l'Atlantique Sud. Se considérant « être plus éloignés de l'Afrique que du pays des Indes occidentales où dempuis aucunes années en çà les Dieppois et les Malouins et autres Normands et Bretons vont quérir du bois à teindre en rouge, cotons, guenons et perroquets et autres denrées ${ }^{114}$, ils décident à l'unanimité de s'y rendre afin de charger une cargaison des marchandises citées qui permettra de rentabiliser le voyage. Les indigènes rencontrés semblent être relativement habitués à voir des Européens aborder sur leurs rivages. Si la première mention attestée d'un voyage normand au Brésil est celui de la Martine de Jumièges en $1518^{115}$, il est évident que les côtes sud-américaines étaient fréquentées depuis environ une vingtaine d'années par les Normands ${ }^{116}$, mais également par les Bretons, qui revendiquaient eux aussi leur titre de premiers occupants dans certains secteurs ${ }^{117}$. Toutefois, comme pour ceux vers la Guinée, ces voyages étaient entrepris secrètement car les

113 J. DE Anchieta, Informação do Brasil e de suas capitanias [1584], L. Arroyo (éd.), São Paulo, Editora Obelisco, 1964, p. 23.

114 Le voyage de Gonneville..., op. cit., p. 26.

115 Arch. dép. Seine-Maritime, Fonds de la Table de marbre de Rouen, 204 BP 1.

116 Voir C. Maneuvrier, M. Daeffler, I. Bretthauer, « Les importations de bois de Brésil en Normandie dans la première moitié du XVI ${ }^{\mathrm{e}}$ siècle ", Revista Portuguesa de História, t. XLVIII, 2018, p. 151-173.

117 BnF, ms. nouv. acq. fr. 9386, fol. 92-96 et 100-110v (copies de Torre do Tombo, Corpo Chronologico, parte 1, maç. 41, doc. 30 et maç. 43, doc. 25). Plusieurs documents relatent la prise de trois navires bretons par les Portugais en 1527 sur les côtes du Brésil et la plainte de cinq marchands bretons « qui comme marchands, fréquentent les mers et diverses terres entre autre celle du Brésil qui sont très grandes et dont une partie a été découverte par les Bretons et l'autre par les Portugais » (fol. 109v). Voir C. DE LA RonciÈre, Histoire de la marine française, op. cit., t. III, p. 131 et 279-280; M. Mollat, Le commerce maritime normand..., op. cit., p. 256, n. 36 ; L.M.R. GuerREIRO, « La prise de trois navires bretons sur les côtes du Brésil en 1527 », dans La Bretagne, le Portugal et le Brésil : échanges et rapports, J.-M. MASSA (dir.), vol. I, Rennes, Association pour le cinquantenaire de la création en Bretagne de l'enseignement du portugais, 1973, p. 103-111. 
navires se rendaient dans des régions réservées officiellement et exclusivement aux Portugais. Aussi les Normands et les Bretons n'étaient pas en mesure d'apporter de preuve formelle de leurs " découvertes " ${ }^{118}$ du Brésil ni de leur présence antérieure à celle de leurs concurrents, comme le déplorait encore $\mathrm{La}$ Popelinière en $1582^{119}$. Leurs voyages ne visaient pas à découvrir et reconnaître des territoires ou à en prendre possession; il s'agissait d'entreprises privées, à des fins exclusivement commerciales et où le plus grand secret était de rigueur.

Quoi qu'il en soit, l'auteur du Discours d'un grand capitaine considère que, quant à la primauté de la découverte, les Français n'ont rien à envier aux Portugais, qui eux, au contraire, avancent principalement cet argument. Depuis longtemps, ils fréquentent régulièrement ces côtes et n'y auraient jamais rencontré de Portugais installés au nom de leur roi. Puis l'auteur se lance dans une véritable diatribe contre les Portugais et leur prétention à exclure les autres nations des terres récemment découvertes, fustigeant notamment leur manque d'ardeur à évangéliser les indigènes et les accusant même de maintenir sciemment ces derniers dans l'ignorance. Pourtant, officiellement, leur expansion est motivée par une volonté de convertir de nouvelles âmes à la foi catholique, mais dans les faits ils se préoccupent seulement de générer d'importants profits commerciaux. Toujours selon l'auteur, les Portugais veulent empêcher les Français de fréquenter ces régions car ils craignent de perdre leur place dans le commerce lucratif du bois-brésil. Effectivement, les marchands français, déjà très bien accueillis, ne manqueraient pas de développer des relations commerciales solides et de grande ampleur, tout en convertissant de nombreux indigènes. Mais pour cela, il faudrait une condition indispensable : l'accord et le soutien de François I ${ }^{\text {er }}$, "s'il voulait lâcher la bride aux marchands de son pays ", au lieu d'user avec les Portugais «d'autant d'humanité et de courtoisie » (fol. 426v) en interdisant à ses compatriotes d'aller commercer dans les régions dont leurs concurrents se prétendent les seuls maîtres.

Le roi de France avait parfois encouragé ou du moins toléré les armements vers les zones théoriquement portugaises, comme en 1530 et en 1533, lorsqu'il délivre des lettres de marque « contre les Portugaloys »-dont une spécialement à Jean Ango - où il affirme la « liberté de naviguer sur la mer commune » ${ }^{120}$.

118 Le terme « découvertes » doit être utilisé avec précaution dans ce contexte particulier où il s'agit de revendiquer une première exploration européenne d'un territoire extra-européen.

119 H. L. V. De La Popelinière, Les Trois Mondes, Paris, P. L'Huillier, 1582, liv. III, art. 6, p. 20 : «Les Frannçois toutesfois, Normans sur tous \& les Bretons, maintiennent auoir premiers descouuerts ces terres : \& d'ancienneté, trafiquer auec les sauuages du Bresil contre la riuiere de sainct François au lieu qu'on a depuis appellé port Real. Mais comme en autres choses mal auisez en celà, ils n'ont eu l'esprit ny discretion de laisser vn seul escrit public pour asseurãce de leurs desseins aussi hautains \& genereux que les autres. Tellement que le Portugais comme de la theorique \& experience au fait des voyages \& descouuertes maritimes, superieurs à toutes nations : aussi en cela se veut il attribuer l'auantage d'en estre paisible seigneur par le moyen de Pedraluarez [Cabral] ».

120 BnF, ms. fr. 5503, fol. 58v et 65. Voir E. GuÉnin, Ango et ses pilotes, op. cit., p. 194-195, 199-200 et la lettre du 27 juillet 1530 délivrée à Jean Ango (p. 249-255, d’après Torre do Tombo, Gav. 3, maç. 1, n. 19). 
En 1533 également, il avait obtenu du pape Clément VII une nouvelle interprétation des partages du monde précédents entre les deux puissances ibériques, qui permettait aux autres nations d'explorer et de prendre possession des terres non encore découvertes par les Espagnols et les Portugais. Mais les circonstances politiques, militaires et diplomatiques, en plus de l'action néfaste du corrompu amiral Chabot et des agents portugais, ont souvent pesé trop lourd pour que la politique maritime du roi soit marquée par la continuité. Au contraire, elle connaît de fréquents revirements.

Par crainte de la puissance grandissante de son éternel rival Charles Quint, François I ${ }^{\text {er }}$ 'employait plutôt à ménager la susceptibilité de son allié le roi du Portugal : d'abord Manuel I ${ }^{\text {er }}$ (1495-1521) - dont il avait épousé en 1530 la veuve Eléonore de Habsbourg, sœur de l'empereur - puis surtout Jean III (1521-1557). Par exemple, en 1531, la lettre de marque de Jean Ango est rachetée par les Portugais et le roi affirme sa volonté qu'aucun navire français ne se rende au-delà de l'archipel du Cap-Vert. Ainsi, cinq navires rouennais en partance pour le Brésil et la Guinée sont saisis à Honfleur sur ordre de l'amiral Chabot. Sur la requête de leurs propriétaires, le conseil de la ville de Rouen décide d'envoyer une délégation à la cour afin d'en connaître les raisons ${ }^{121}$. Peu après, un navire chargé de marchandises venues de Guinée accoste à Rouen, déclenchant la colère de l'ambassadeur portugais Gaspar Vaz ${ }^{122}$. Plus encore, ce dernier signale à Jean III que les navires saisis ont finalement quitté Honfleur, tandis qu'un est parti de La Rochelle et deux autres de Brest ${ }^{123}$. Pendant ce temps, les Portugais avaient intercepté la Pèlerine, un navire parti de Marseille et de retour du Brésil. Apprenant ainsi une tentative d'établissement français sur l'île de Saint-Alexis, près de Pernambouc, Jean III envoya aussitôt une escadre menée par Lopes de Sousa pour y mettre fin brutalement en décembre $1531^{124}$.

Malgré les interdictions, dans les années suivantes les Normands continuent d'armer pour ces destinations prohibées, provoquant de nouveaux conflits avec

121 Arch. dép. Seine-Maritime, 3E001 ANC A13 Rouen (1528-1534), fol. 153v-154, 26 août 1531. Le conseil craint les « grans dommages qui adviendroient a ladite ville si voyages estes empeschez, considéré que la pluspart des habitants d'icelle sont fondez et leur maniere de vivre deppende de la traffique des marchandises qui se font par la mer ». Voir E. GuÉnin, Ango et ses pilotes, op. cit., p. 198, qui résume un document portugais donnant les noms des navires et de leurs capitaines, ainsi que leur tonnage (Torre do Tombo, Corpo Chronologico, parte 1, maç. 49, doc. 33). Voir la copie complète du document suivie d'une traduction en français : BnF, ms. nouv. acq. fr. 9386, fol. 313-316.

122 BnF, ms. nouv. acq. fr. 9386, fol. 161-168 (copie de Torre do Tombo, Corpo Chronologico, parte 1, maç. 47, doc. 43) ; lettre du 4 septembre 1531.

$123 \mathrm{BnF}, \mathrm{ms}$. nouv. acq. fr. 9386, fol. 211-217v (doc. 75) ; lettre du 19 octobre 1531. Il en avait été informé par l'un de ses agents, Belchior Rapozo, dans une lettre datée du 27 septembre (fol. 197-203, doc. 61).

124 Voir C. DE La Roncière, Histoire de la marine française, op. cit., t. III, p. 280-282, et E. GUÉNIN, Ango et ses pilotes, op. cit., p. 43-47 et 256-261, qui reproduit la protestation de l'armateur du navire, le baron de Saint-Blancard, général des galères de François ${ }^{\mathrm{er}}$. 
les Portugais ${ }^{125}$. Les deux royaumes étant officiellement en paix, François ${ }^{\text {er }}$ rappelle en 1536 que les prises doivent être restituées " sous peine de châtiment pour avoir rompu et violé la paix » et demande, " pour que nul ne puisse alléguer cause d'ignorance ", que ces dispositions soient lues et publiées «à son de trompe et cri public en tous nos ports, havres et autres lieux où il sera nécessaire ${ }^{126}$. Quelques jours plus tard, à la suite des plaintes de l'ambassadeur de Jean III, il s'adresse spécifiquement à ses officiers en Normandie, leur enjoignant de saisir les "violateurs et briseurs de paix » coupables de prises de navires portugais afin qu'ils restituent leur butin ou sa valeur et que cela serve d'exemple ${ }^{127}$.

L'année suivante est mis en place à Bayonne un tribunal des prises composé de juges français et portugais, mais qui ne sera jamais véritablement efficace $^{128}$. Parallèlement, le roi de France interdit à tous ses sujets de commercer « aux terres de Bresil ne Mallaguette ny aus terres descouvertes par les roys de Portugal » par lettres patentes du 30 mai 1537, confirmées le 23 août suivant ${ }^{129}$. D'après Jean Nicot, ambassadeur de France à la cour de Lisbonne qui revendique toujours la liberté des mers vingt ans plus tard dans une lettre adressée au roi François II le 12 décembre 1559, après avoir été publiées à Rouen et au Havre les 14 et 25 février 1538, les lettres patentes du roi auraient encore été renouvelées au mois de septembre suivant ${ }^{130}$. Mais, en dépit des interdictions et des intimidations ${ }^{131}$, les Normands poursuivent leurs activités, entraînant les « remonstrances » des Portugais. François $\mathrm{I}^{\text {er }}$ doit à nouveau intervenir le 22 décembre 1538 auprès du Parlement de Rouen en

125 C. de la Roncière (Histoire de la marine française, t. III, p. 286) signale (vers 1532-1533 ?) les cas, entre autres, de trois navires armés par Jean Ango : la Michelle, capturée par les Portugais au Brésil et l'Alouette et la Musette, attaquées dans le golfe de Guinée. L'Alouette parvint tout de même au large du Brésil, où elle dut battre en retraite face aux canons portugais (d'après une lettre de marque délivrée par François $1^{\text {er }}$ à Jean Ango le 3 février 1544, citée par E. Guénin, Ango et ses pilotes, p. 149-151).

126 Lettres du 8 août 1536, Torre do Tombo, Corpo Chronologico, parte 1, maço 57, doc. 80. Le texte portugais est publié avec une traduction en français dans les Ordonnances de François $I^{\text {er }}$, t. VIII (Appendices, index et tables 1536-1537), Paris, Imprimerie nationale, 1972, p. 593-595.

127 Lettres du 27 août 1536, ibid., doc. 94, p. 595-598.

128 Voir M. Mollat, « De la piraterie sauvage à la course réglementée (XIV $-\mathrm{XV}^{\mathrm{e}}$ siècle) », Mélanges de l'École française de Rome. Moyen Âge-Temps modernes, t. 87, n 1, 1975, p. 20-23.

129 Ces deux documents, qui semblent perdus, nous sont connus par des mentions ultérieures, notamment dans les lettres de François $\mathrm{I}^{\mathrm{er}}$ du 22 décembre 1538 citées plus bas. Ils sont signalés dans le Catalogue des actes de François $I^{e r}$, t. VIII, Paris, Imprimerie nationale, 1905, p. 657, n 32696 et p. 661, $\mathrm{n}^{\circ}$ 32716, avec des cotes au British Museum de Londres, ms. Cotton, Nero, B. 1, fol. 69 et 102.

$130 \mathrm{BnF}$, nouv. acq. fr. 6638, fol. 61. Voir aussi Jean Nicot, ambassadeur de France en Portugal au XVI e siècle. Sa correspondance diplomatique inédite, E. FAlgairolle (éd.), Paris, Challamel, 1897, p. 43, avec des erreurs de dates.

131 En 1537, le Petit-Lyon, armé par le marchand dieppois Guillebert Scot, fut capturé par les Portugais aux Açores, et son équipage soumis à des supplices cruels avant d'être assassiné. Voir C. DE LA Roncière, Histoire de la marine française, op. cit., t. III, p. 292-293, et E. GuÉnIn, Ango et ses pilotes, op. cit., p. 235 sq. 
chargeant ses officiers d'enquêter sur les déprédations et infractions commises et de proclamer à nouveau ses interdictions ${ }^{132}$.

Le 9 janvier 1539, le conseil de la ville de Rouen débat de la conduite à tenir et la majorité de ses membres envisage l'envoi d'une délégation à la cour, non sans « colloquer avec les aultres baillages » ${ }^{133}$. La décision est prise le 22 janvier : tout en sollicitant l'appui de " tous aultres marchans de Paris, Troyes, Orleans et toutes aultres villes [...] pour dune mesmes poursuitte et faire les remonstrances au prince ", une députation va se rendre auprès de François I ${ }^{\text {er }}$ afin de lui présenter les doléances des marchands rouennais ${ }^{134}$. Alors que l'interdiction royale est encore peut-être signifiée au Parlement de Rouen le 24 ou le 25 janvier $^{135}$ (ou en février selon Jean Nicot ${ }^{136}$ ), la délégation rouennaise est déjà signalée de passage à Vigny (Val-d'Oise actuel) le 28 janvier, avec le soutien de certains confrères parisiens, eux aussi lésés par cette mesure ${ }^{137}$.

Nous émettons l'hypothèse que le Discours d'un grand capitaine a été rédigé précisément à ce moment, en janvier 1539, afin de servir de support aux délégués rouennais, qui avaient besoin d'arguments concrets à présenter au roi pour tenter d'infléchir sa position. Cette diatribe contre les prétentions portugaises constitue un véritable plaidoyer. Il s'agit d'un pamphlet ardent en faveur du commerce français au Brésil en particulier, et de la liberté des mers en général, s'opposant de manière virulente à la politique de la mare clausum des Portugais. C'est une protestation argumentée contre les interdictions royales émises, qui devaient être régulièrement renouvelées car justement les Normands,

132 Arch. dép. Seine-Maritime, 3E001 ANC A14 Rouen (13 mai 1535-22 juillet 1541), fol. 283-286v. Cet acte a été publié par E. DE FrÉVILLE, Mémoire sur le commerce maritime de Rouen, depuis les temps les plus reculés jusqu'à la fin du XVI siècle, Rouen, Le Brument, 1857, t. II, n CXII, p. 437-439; par J. Thieury, Le Portugal et la Normandie jusqu'à la fin du XVI e siècle, Paris, Aubry, 1860, p. 98-102; par E. GuÉnin, Ango et ses pilotes, op. cit., p. 203-205, ainsi que dans les Ordonnances de François I ${ }^{e r}$, t. IX, $2^{\mathrm{e}}$ partie (4 décembre 1538-mai 1539), Paris, Imprimerie nationale, 1975, n 884, p. 256-261.

133 Ibid., fol. 278v-280. Face à cette « commission [qui] a totallement ruyné la navigation de la mer », il est proposé d'« envoyer une grosse et notable compaignie devers le roy lui faire entendre les inconveniens, consequence et importance de ladite commission ».

134 Ibid., fol. $280 \mathrm{v}-282$ : « de cent ans nont esté mis ses deux poinctz de si grand domage a la chose publique du pays, et on ne pourroit inventer moyens pour plus tost faire notre perte de villes de ce pays, singullierement en ceste ville auquelz deux pointz il a esté necessaire par tous moyens resister par remonstrance et faire entendre la consequence et grand domage et ruyne de ses subgectz »; «Les maistres des navires se retireront en aultres pays hors le royaulme. On doibt remonstrer lesdits inconveniens au roy »; " pour remonstrer les grandz dommages et inconveniens de la deffence ordonnee par le roy ».

135 Le Catalogue des actes de François I r $^{e}$ signale à deux reprises (t. III, p. 704, n 10731 et t. VIII, p. 681, n³2829) un « Mandement au Parlement de Rouen contenant défenses à tous marchands et marins d'envoyer des navires à la Guinée ou au Brésil, donné à la requête du roi de Portugal ». Mais d'après les Ordonnances de François $I^{e r}$, t. IX, $2^{e}$ partie, p. 260, n. 2, il s'agirait d'une erreur.

136 BnF, nouv. acq. fr. 6638, fol. 61-62 ; Jean Nicot..., op. cit., p. 43-44. Nicot mentionne, sans indiquer aucune date, des doléances portées à la cour par des marchands normands afin de solliciter la révocation des interdictions royales, ainsi que «plusieurs jussions » adressées au parlement de Rouen afin de « proceder à la publication desdites lettres ».

137 Registres des délibérations du Bureau de la ville de Paris, t. II (1527-1539), A. Tuetey (éd.), Paris, Imprimerie nationale, 1886, p. 400 et note 2 (6 février 1539). 
entre autres, les bravaient ${ }^{138}$. À tel point qu'en 1540 les Portugais devaient encore envoyer une expédition à la côte de la Malaguette afin de chasser leurs concurrents $^{139}$, tandis que le frère du roi du Congo, Dom Manuel, demandait à Jean III, par crainte des Français, de lui fournir une caravelle bien armée pour le conduire au Portugal puis à Rome ${ }^{140}$. Ce n'est qu'après l'arrestation puis le procès de l'amiral Chabot, convaincu de concussion et de prévarication en faveur des Portugais, que la défense d'aller commercer au Brésil et en Guinée fut enfin levée par François $\mathrm{I}^{\text {er }}$ le 13 novembre $1540^{141} \ldots$ avant d'être rétablie par Henri II dès le début de son règne le 20 octobre $1547^{142}$.

Selon nous, le Discours d'un grand capitaine a donc été rédigé en janvier 1539, tout en contenant des descriptions et des informations datant incontestablement de plusieurs années et d'époques différentes.

\section{L'auteur et le "grand capitaine de Dieppe»}

Qui est l'auteur de ce texte mystérieux ? Et qui est ce fameux capitaine dont l'identité n'est pas plus dévoilée ? Pour l'historiographie, il ne fait quasiment aucun doute qu'il s'agit respectivement de Pierre Crignon, l'auteur du journal de bord du Sacre et de la Pensée en 1529, et de Jean Parmentier, le commandant de cette expédition. L'un des principaux arguments de ces différents auteurs (entre autres : C. Schefer, P. Margry, H. Harrisse, G. Musset ${ }^{143}$, l'abbé Anthiaume, C. de la Roncière, C.-A. Julien, et plus récemment J. Nothnagle et B.G. Hoffman) est que la dernière partie du Discours d'un grand capitaine évoque le même séjour à Ticou. Si cette double identification ne peut pas être

138 Par exemple, en 1539, le Rouennais Nicolas Guincestre fit à bord de la Madeleine un voyage fructueux « au Brésil et en la terre des Cannibales » et rentra à Fécamp (Documents authentiques..., op. cit., p. 142-143, Tabellionage, 3 février 1540). En 1540, un navire breton revenant de Guinée, le Jean, fut arrêté à La Rochelle sur les instances de l'ambassadeur du roi du Portugal (É. Trocmé, M. Delafosse, Le commerce rochelais de la fin du XV siècle au début du XVII , Paris, Armand Colin, 1952, p. 98).

139 D'après l'historien portugais Fernando Palha. Voir « La lettre de marque de Jean Ango. Exposé sommaire des faits d'après des documents originaux et inédits, par Fernando Palha. Traduit du portugais par R. Francisque-Michel », Bulletin de la Société normande de géographie, 1889, p. 380.

140 Lettre de Dom Manuel à Jean III, 12 juillet 1540, Torre do Tombo, Gaveta 15, maço 18, doc. 10, traduit en français et cité dans la Correspondance de Dom Afonso, roi du Congo, 1506-1543, L. JADIN et M. Dicorato (éd.), Bruxelles, Académie royale des sciences d'outre-mer, 1974, nº 78, p. 213-214.

141 BnF, Cinq Cents Colbert, 292, fol. 39v-40. Est mentionnée une « declaration de françois premier par laquelle sur la priere des marchands il revocque les deffenses faictes a la requisition de l'ambassadeur de Portugal a tous françois d'aller au Bresil ne a la malaquette, veut qu'ils y puissent aller de la en avant a la charge de n'aller ny naviger sur les lieux et terres apartenantes aud. Roy de Portugal sinon que ce soit de sa permission et de n'user d'aucunes depradations sur ses suiects ».

142 Bnf, ms. fr. 18153, fol. 9-9v.

143 Celui-ci va plus loin en estimant que ce sont les voyages et les écrits de Jean Alfonse de Saintonge qui ont servi de base au Discours d'un grand capitaine. Pourtant, le manuscrit de sa Cosmographie est daté de 1544-1545 et ses Voyages aventureux n'ont été publiés qu'en 1559. Voir La Cosmographie..., G. Musset (éd.), Paris, Leroux, 1904, «Introduction », p. 34-35, qui renvoie à H. Harrisse, Découverte et évolution cartographique de Terre-Neuve et des pays circonvoisins, 1497-1501-1769, Paris, Welter, 1900 , p. $150-153$. 
totalement écartée, ce raccourci nous semble quelque peu hâtif et discutable ; il pose question en tout cas.

\section{Informations sur Pierre Crignon}

Pierre Crignon était un homme lettré dieppois, doté d'une solide culture classique, comme le montrent plusieurs passages de son journal. Comme son ami Jean Parmentier, c'était un poète : il remporta plusieurs prix de poésie au puy de l'Assomption à Dieppe ainsi qu'au puy de la Conception de Rouen (en 1515, 1517 et 1527), et ses vers ont été imprimés dans les recueils de cette académie $^{144}$. Embarqué à bord de la Pensée en tant qu'astrologue, il était forcément très compétent en matière de cosmographie et de navigation; c'est lui qui faisait le point quasi quotidiennement et estimait la position des navires en latitude. Il était l'un des principaux officiers de l'expédition, jouant un rôle important à plusieurs reprises.

À son retour en France, Crignon rassembla les vers de Jean Parmentier qui, tout comme son frère Raoul, avait trouvé la mort à Sumatra. Il les publia en 1531 sous le titre Description nouvelle des merveilles de ce monde, et de la dignité de l'homme $e^{145}$. On y trouve notamment le traité que Jean composa au cours du voyage afin d'encourager ses compagnons, dont le moral était ébranlé par les privations, les maladies et le mal du pays, à poursuivre l'aventure : Traicté en forme d'exhortation, contenant les merveilles de Dieu et la dignité de l'homme [...]. Crignon y ajouta un « Prologue » contenant l'éloge des deux frères, ainsi que l'un de ses propres poèmes, intitulé Plaincte sur le trespas de deffunctz Jean et Raoul Parmentier ${ }^{146}$. Il rédigea en 1534 un traité, resté manuscrit mais aujourd'hui perdu, portant sur « les variations de l'aiguille aimantée ${ }^{147}: L a$ Perle de cosmographie, dédié à l'amiral de France, Philippe de Chabot. Il prétendait y dévoiler « le secret des longitudes ${ }^{148}$, dont le calcul ne put être effectué avec précision que grâce à l'invention du chronomètre à la fin du XviII ${ }^{\mathrm{e}}$ siècle. Enfin, seul le chroniqueur dieppois M.-C. Guibert avance une date incertaine pour la mort de Pierre Crignon : vers $1540^{149}$.

144 BnF, ms. fr. 379, 2202 et 2205 ; Rouen, Bibliothèque municipale, ms. fr. 1062 Y 18.

145 BnF, Rés. Ye 205 (disponible sur Gallica). Le volume est relié avec une édition du Miroir de l'ame pecheresse de Marguerite de Navarre, imprimée la même année à Alençon.

146 Voir J. Parmentier, Euvres poétiques, F. Ferrand (éd.), Genève, Droz (Textes littéraires français ; 175), 1971, où sont publiés le «Prologue », le Traicté et la Plaincte, respectivement p. 2-5, 91-113 et 131-141 (les citations sont issues de cette édition), avec une biographie de Jean Parmentier (p. XI-XIX).

147 Le discours de la navigation..., C. SchefER (éd.), p. XXI.

148 Tout ce que l'on sait de ce traité est dû à une note du géographe Guillaume Delisle (1675-1726), citée par C. Schefer (ibid., p. XXI-XXII, n. 2).

149 M.-C. Guibert, Mémoires pour servir à l'histoire de la ville de Dieppe, publiés par M. Hardy, Dieppe, A. Renaux et A. Leblanc - Paris, Maisonneuve et $C^{\text {ie }}$ - Rouen, C. Métérie, 1878, t. I p. 357 : «Vers 1540, [décéda] Pierre Crignon, poëte françois ». 


\section{Informations sur Jean Parmentier}

À travers le récit du voyage à Sumatra et la publication des vers de son ami, Crignon représente notre principale source d'informations sur Jean Parmentier. Son témoignage est donc à manier avec précaution, car il est effectué en son honneur, à son avantage, et contient inévitablement des déformations, des exagérations et va même parfois jusqu'à l'hagiographie. Crignon nous apprend que les deux frères Parmentier étaient «bourgoys et marchantz de la ville de Dieppe, hommes de bon esprit et profundz en la science de astrologie et cosmographie $»^{150}$. Jean était à la fois poète, humaniste, marin, cosmographe et géographe. Il était une sorte d'autodidacte, doué d'une forte personnalité, d'une ferme volonté et d'un esprit universel, bref un grand érudit ${ }^{151}$. Crignon le présente comme " bon cosmographe et geographe : par luy ont esté composéz plusieurs mapesmondes en globe et en plat et maintes cartes marines sur lesquelles plusieurs ont navigué seurement ${ }^{152}$, mais aucune de ses œuvres n’a été conservée.

Il était très connu en Normandie pour ses œuvres littéraires et poétiques, ayant été à trois reprises lauréat des Palinods de Rouen (en 1517, 1518 et 1520) et ayant remporté les plus hautes récompenses aux puys de l'Assomption à Dieppe. D'après Crignon, "C'estoit une perle en rhetorique françoyse et en bonnes inventions, tant en rithme qu'en prose $»^{153}$. Érudit latiniste, il avait traduit en 1528 l'Histoire catilinaire de Salluste ${ }^{154}$, qu'il avait dédiée à son ami l'armateur Jean Ango. Il commença également au cours de son voyage vers Sumatra une traduction du Jugurtha du même auteur, qu'il destinait au roi mais qu'il ne put achever.

Au-delà de l'objectif de l'expédition qu'il menait (ouvrir la route des Indes orientales à la France et y disputer le commerce des épices aux Portugais), ses motivations personnelles étaient selon Crignon, non pas l'appât du gain, mais la passion de connaître, la découverte de l'inconnu, la gloire du Roi et l'honneur de la France, ainsi que la gloire personnelle d'être le premier capitaine français à parcourir ces mers ${ }^{155}$.

150 P. CRignon, « Prologue », p. 2.

151 Ibid., p. 3 : «Et combien qu'il n'ait pas beaucoup hanté les escolles, sy toutes fois estoit il congnoissant en plusieurs sciences que le grant Precepteur et Maistre d'escolle, par don de grace infuse, luy avoit eslargi ».

152 Ibid., p. 4.

153 Ibid.

154 L'hystoire catilinaire composée par Salluste, hystorien romain et translatée par forme d'interprétation d'ung tres bref et elegant latin en nostre vulgaire françois, par Jan Parmentier, bourgois et marchant de la ville de Dieppe, Paris, imprimé par Symon Duboys pour Jean Pierre de Tours, 1528 (Londres, British Museum, 587 d. 25). Une édition de 1536 est conservée à la bibliothèque municipale d'Avignon ( $\left.8^{\circ} 12997\right)$. Il en existe une troisième, datée de 1539.

155 Voir J. PARMENTIER, Traicté, p. 91-92. Crignon ajoute : « il desiroit fort honneur en toutes choses » (« Prologue », p. 3) et : « Desir d'honneur te faict faire ce tour » (Plaincte, p. 132). 
Quelle expérience avait-il de la navigation océanique ? Dans la dédicace de sa traduction de Salluste (1528), il nous apprend lui-même qu'il avait déjà voyagé pour le compte de Jean Ango, sans indiquer dans quels secteurs : « depuis six ans en ça, en commenceant soubz ton service, Cosmographie m'a faict exercer sa praticque sur les grosses et lourdes fluctuations de la mer, en qui n'est doulceur ne plaisir ${ }^{156}$. Pour qu'il commande une expédition vers les lointaines îles aux épices, Jean Parmentier était forcément un capitaine expérimenté ; d'après Crignon, il était âgé de 35 ans en $1529^{157}$. Mais il n'a certainement pas effectué un premier voyage jusqu'à la Chine, comme le mentionne le chroniqueur dieppois - peu fiable - Charles Desmarquets, qui lui attribue même un projet de tour du monde mis au point avec Jean Ango, avorté en raison de sa mort prématurée ${ }^{158}$. Crignon, beaucoup plus crédible, affirme qu'il est « le premier Françoys qui a entrepris à estre pillotte pour mener navires à la terre amerique qu'on dict le Bresil ${ }^{159}$, ce qui semble contredire l'extrait du Discours d'un grand capitaine attribuant au Honfleurais Jean Denis la primauté de cette découverte (fol. 426v), à moins qu'il ne soit question de deux régions différentes du Brésil.

Jean Parmentier est mort des fièvres au large de Sumatra le 3 décembre 1529 quelques jours avant son frère Raoul, laissant une épouse et deux jeunes enfants.

\section{Discussion}

Pierre Crignon, en tant qu'astrologue de la Pensée, possédait évidemment les compétences nécessaires pour rédiger la partie introductive du Discours d'un grand capitaine, consacrée à une explication technique sur la longitude et de la latitude. Mais, comme le suggère Estancelin ${ }^{160}$, ce passage pourrait tout aussi bien avoir été rédigé par Pierre Mauclerc, l'astrologue du Sacre à propos duquel nous ne savons rien. Ou encore par n'importe quel cosmographe, même si l'expression "selon les cosmographes » (secondo li cosmographi), employée dès la troisième ligne du texte (fol. 423), semble vouloir signifier que l'auteur ne

156 Cité dans J. Parmentier, Euvres poétiques, F. Ferrand (éd.), p. 120.

157 Jean et Raoul Parmentier étaient « aagéz l'un de trente cinq et l'aultre de trente ans » (« Prologue », p. 2).

158 C. Desmarquets, Mémoires chronologiques pour servir à l'histoire de Dieppe et à celle de la navigation françoise, Paris, Desauges, 1785, t. I, p. 111-113 et t. II, p. 10-11. Ces mémoires sont fortement sujets à caution, notamment car ils attribuent à un autre Dieppois, Jean Cousin, la découverte du Brésil et de la pointe sud de l'Afrique en 1488-1489, et même la première liaison avec les Indes orientales (t. I, p. 91-99).

159 P. CRignon, «Prologue », p. 3. Crignon poursuit en évoquant les projets ambitieux de son ami : «Et semblablement, le premier Françoys qui a descouvert les Indes jusques à l'isle de Taprobane ; et, sy Mort ne l'eüst parvenu, je croy qu'il eust esté jusques aux Moluques. Et, ainsy qu'il m'a dict plusieurs fois, il estoit bien deliberé, luy retourné en France, de aller cercher s'il y a ouverture au Nort, et descouvrir par là jusques au $\mathrm{Su}$ ». Un passage du Traicté semble aller également dans ce sens : « Encores plus, je ne me rassasie / si je ne passe oultre les fins de Asie » (p. 91).

160 Estancelin, p. 45, n. 1. 
se considère pas comme tel, se démarquant même d'eux en prenant un autre point de repère pour le calcul de la longitude.

La suite du texte, où sont décrites les côtes de l'Amérique du Nord, du Brésil, de la Guinée et certaines de leurs populations, est rédigée de manière impersonnelle et ne délivre pas d'indice sur la personnalité de l'auteur, à l'exception de la diatribe contre les prétentions portugaises au Brésil, qui révèle un arrière-fond commercial. Il peut tout à fait s'agir de Pierre Crignon, qui aurait pourquoi pas parcouru lui-même ces contrées en accompagnant son ami Jean Parmentier. Mais n'importe quelle personne bien renseignée, même un « cosmographe de cabinet " ${ }^{161}$, a pu également recueillir toutes ces informations décrivant des régions alors fréquentées régulièrement par les navires normands.

La dernière partie du Discours d'un grand capitaine, une fois le rapprochement fait avec le voyage du Sacre et de la Pensée à Sumatra, a amené son attribution à Pierre Crignon et l'identification du « grand capitaine » avec Jean Parmentier. Pourtant, à notre avis, c'est celle qui pose le plus de questions. D'abord, comme on l'a déjà vu, par son style et son ton, qui se distinguent du reste du texte car l'auteur de ce passage a vécu lui-même les événements. Mais s'agit-il de Pierre Crignon? Rien n'est moins sûr. Une comparaison avec le récit des Parmentier, qui mériterait d'être plus approfondie, montre que si les deux documents contiennent logiquement des similarités, on y note aussi des différences notables et difficiles à expliquer. Par leur nature d'abord : le récit des Parmentier, rédigé par Crignon, est un journal de bord complet et précis, allant du départ de Dieppe à celui de Sumatra, tandis que le court extrait du Discours d'un grand capitaine est brièvement consacré aux mœurs des habitants de Ticou. Par leur contenu ensuite : selon le récit des Parmentier, après un accueil d'abord amical et même la conclusion d'une alliance, les contacts avec la population ont été tendus et le commerce extrêmement difficile. La mauvaise volonté des indigènes est mise en avant, y compris celle du roi et de ses officiers (dont le "Chabandaire » / Chambendare »), décrits comme étant naturellement très durs en affaires, malhonnêtes et qui marchandent beaucoup trop ${ }^{162}$. Dans une ambiance hostile et menaçante, des otages sont

161 Par opposition aux « cosmographes de plein vent » chers à Lucien Febvre. Voir L. Febvre, Le problème de l'incroyance au XVI siècle : la religion de Rabelais, Paris, Albin Michel, 1968, p. 357 ; et F. Lestringant, L'atelier du cosmographe ou l'image du monde à la Renaissance, Paris, Albin Michel, 1991, p. 27-35: «Une cosmographie de plein vent ».

162 Voir Le discours de la navigation..., C. SChefer (éd.), p. 64-69 et 75-76. Par exemple : « Dieu sçait les belles promesses que ledit Chabandaire nous fit, tant de nous faire bien vendre nos marchandises, que de nous faire charger du poivre» (p. 65) ; «ils sont fins et astucieux, grands flatteurs, grands menteurs et moqueurs ; parmi fort marauts, toujours demandans ; qui eust voulu obtempérer à leur requeste, nous n'avions point marchandise pour y fournir. En marchandise, ils sont grands barguigneux plus que Escossois ou Houivests. Car, après marché fait, ils veulent rabatre du prix, ou bien se dedisent ; et n'est si sage qui aucune fois n'en fut courroucé contre eux ; mais nous le portions plus patiemment, pour ce que nous voyons bien que c'estoit la coutume du pays, car le roy et les plus grands estoient tous faits en 
échangés et, selon une autre source ${ }^{163}$, plusieurs indigènes auraient même été exécutés par les Français. Or, dans le Discours d'un grand capitaine, il n'est fait aucune mention de tout cela, au contraire : «Ce sont d'assez bonnes personnes, pacifiques, mais astucieux et subtils dans leurs trafics et leurs façons de marchander, et ils tiennent leur parole dans les négociations» (fol. 432). Enfin, la courte conclusion est encourageante et positive : «Et de là, après avoir chargé nos navires de poivre et d'autres épices, nous retournâmes à Dieppe sains et saufs après une si longue et périlleuse navigation [entreprise] en l'honneur de Dieu et de la Couronne de France » (fol. 432v). Elle laisse croire que le voyage s'est très bien déroulé et que les navires sont rentrés sans encombre en France chargés d'épices, ce qui s'avère pour le moins éloigné des événements décrits dans le récit des Parmentier. Il n'est pas fait mention, par exemple, des deux autres escales effectuées par la suite sur la côte de Sumatra, ni surtout des importantes difficultés à commercer et des fortes tensions avec les indigènes à Ticou, pas plus que de la mort, à cause du scorbut et des fièvres, de nombreux membres d'équipage, et en particulier des deux capitaines Jean et Raoul Parmentier. De plus, le Sacre et la Pensée ne rapportèrent qu'une faible cargaison de poivre. On peut considérer que leur voyage fut un échec commercial, sans doute assez décourageant car, même s'il ne s'agit certainement pas de la seule explication, on ne connaît aucune autre tentative française vers les îles aux épices avant l'expédition du Corbin et du Croissant, partie de Saint-Malo en... 1601.

Ainsi, il paraît assez incertain que Pierre Crignon soit l'auteur de la partie du Discours d'un grand capitaine consacrée à Sumatra ${ }^{164}$, même si on ne peut pas l'exclure totalement. Ayant rédigé lui-même le récit de l'expédition, pourquoi n'aurait-il transmis qu'un abrégé du séjour à Ticou ? Expliquant l'avoir fait afin que le nom des Parmentier ne sombre pas dans l'oubli ${ }^{165}$, pourquoi n'aurait-il pas mentionné l'identité de son ami ? Nous proposons l'hypothèse

ce moule $[. .]$.$» ; « le Chabandaire [. .$.$] vouloit que nous donnassions la marchandise à vil prix : parquoy$ nos capitaines l'eurent en haine » (p. 75-76).

163 Il s'agit d'une lettre, datée de Dieppe le 18 septembre 1575, relatant le bref témoignage d'un des derniers survivants de l'expédition, quarante-cinq ans après les faits : Jean Plastrier, âgé de 80 ans, qui était pannetier à bord du Sacre. Le pannetier était chargé de la garde et de la distribution du pain, ou bien un artisan fabriquant des perles en os pour des chapelets, des boutons, etc. La lettre a été publiée par C. Schefer dans son édition du Discours de la navigation..., p. 1-4.

164 C'est également l'avis de M. Wintroub dans son ouvrage paru très récemment : The Voyage of Thought. Navigating Knowledge across the Sixteenth-Century World, Cambridge, Cambridge University Press, 2017, p. 229-238.

165 «[...] je, qui tousjours ay acompaigné ledict Jan Parmentier en tous perilz et dangiers durant le dict voyage, et jusques au dernier jour, ainsy que l'un de ses plus privéz et familliers amys, pour la recreation de tous nobles et vertueux espritz qui se delectent et prennent plaisir à veoir et ouïr parler de la cosmographie et en ce, contempler et adviser les merveilles que Dieu a faict au ciel, en la terre et en la mer, ay bien voulu, en obtemperant aux importunes requestes d'aucuns mes amis et familiers, rediger par escript la dicte navigation et voyage, et icelle description mettre et produire en lumiere, affin que le nom des dictz Parmentiers ne demeure ensevely avec leurs corps en la dicte ille de Samatra, mais que, en triumphant sus la mort, ilz puissent revenir en la memoire des hommes, par renommée et louenge immortelle » (P. CRignon, Prologue, p. 2-3). Par ailleurs, dans sa Plaincte, Crignon souhaite que le nom 
suivante : l'auteur de cette partie ne serait pas Crignon, mais il s'agirait d'un autre témoin du même voyage. Ou bien encore, on pourrait envisager avec beaucoup de précaution qu'il s'agisse là de deux voyages dieppois différents à Sumatra, dont un qui resterait ignoré dans l'état actuel de nos connaissances, mais cela parait improbable.

Jean Parmentier n'est sans doute pas non plus le fameux " grand capitaine ». Rappelons l'extrait du Discorso sopra la terra ferma... déjà cité, dans lequel Ramusio évoque brièvement le Discours d'un grand capitaine:

A été ensuite ajouté un écrit, ou nous voulons dire un discours fait en 1539 par un grand capitaine français, que nous avons voulu traduire de sa langue dans la nôtre, où il décrit le voyage qui se fait à la terre neuve des Indes occidentales, quon appelle à présent la Nouvelle France, et aussi à la terre du Brésil, qui fait également partie desdites Indes, à la Guinée, à la côte de la Malaguette en Afrique, que tous les jours les Français fréquentent avec leurs navires. Par la suite ce capitaine, avec deux navires armés à Dieppe en Normandie, voulut aller jusqu'à l'île Taprobane, au Levant, à présent nommée Sumatra, où il négocia avec ces peuples et, chargé d'épices, revint chez lui ${ }^{166}$.

Selon nous, il est question ici, de manière générale, des voyages effectués régulièrement (il viaggio, che si fa) par les Français en Amérique et en Afrique, mais que le "grand capitaine " n'a pas forcément réalisé lui-même. $\mathrm{Au}$ contraire, le seul voyage auquel il a pris part personnellement est celui qui l'a mené à Sumatra. Le dernier extrait indiquant son retour (ritorno à casa), sans doute inspiré de la conclusion du Discours d'un grand capitaine, ne peut pas correspondre avec Jean Parmentier, mort au large de Sumatra le 3 décembre 1529, à moins que cette information fondamentale n'ait été cachée volontairement ; nous y reviendrons plus loin.

Reprenons également le titre complet: Discours d'un grand capitaine de mer français du lieu de Dieppe sur les navigations faites à la nouvelle terre des Indes occidentales appelée la Nouvelle France, du $40^{\circ}$ au $47^{\circ}$ degré sous le pôle arctique, et à la terre du Brésil, en Guinée, à l'île de Saint-Laurent et à celle de Sumatra, jusqu'auxquelles ont navigué les caravelles et les navires français. Là encore, il ne semble pas être question d'un seul capitaine qui aurait effectué tous ces voyages, mais plutôt des navigations réalisées régulièrement par les Français dans tous les secteurs cités. Un extrait situé dans la partie introductive va dans le même sens : "Or, pour en venir à notre sujet principal et pour faire la description des terres visitées selon la carte marine » (fol. 423). Cela ne donne pas vraiment l'impression que toutes ces terres ont été visitées par le même capitaine.

de « Parmentiere » soit donné à la mer où sont morts les frères Parmentier, pour en faire « memoire à tout jamais » (p. 140).

166 Navigationi et viaggi, vol. III, éd. 1556, fol. 417v. 
Les auteurs qui ont attribué tous ces voyages à Jean Parmentier s'appuient selon nous sur deux principaux éléments. Le premier est l'extrait de la dédicace de sa traduction de Salluste (1528) cité plus haut, selon lequel « depuis six ans en ça, en commenceant soubz ton service, Cosmographie m'a faict exercer sa praticque sur les grosses et lourdes fluctuations de la mer, en qui n'est doulceur ne plaisir ${ }^{167}$. Effectivement, on peut déduire de cette phrase que Jean Parmentier a largement « bourlingué » avant de partir pour les Indes orientales et tenir pour acquis qu'il possédait une certaine expérience, indispensable pour que lui soit confié le commandement de deux navires à destination des Indes orientales. Mais on ne peut pas pour autant avoir de certitude sur les mers et les côtes parcourues. La rigueur scientifique amène plutôt à ne retenir comme certain que son voyage au Brésil évoqué par Crignon dans son " Prologue » : "le premier Françoys qui a entrepris à estre pillotte pour mener navires à la terre amerique quon dict le Bresil ${ }^{168}$.

Le second élément est une source postérieure de plus d'un siècle, l'Hydrographie du père Georges Fournier (1643), qui confirmerait ce voyage en le datant précisément : « L'an 1520. trois freres ${ }^{169}$ nommez les Parmentiers natifs de Diepe, excellents Mariniers, partirent de Diepe pour faire découuerte, descendirent à Fernambouc, d'où ils apporterent du bois de Bresil ${ }^{170}$. Le père Fournier, jésuite normand, géographe, hydrographe, mathématicien, ayant une expérience personnelle de la navigation, est en général considéré comme un auteur fiable ${ }^{171}$. Sa célèbre Hydrographie, première encyclopédie maritime française, est vue comme une source de premier ordre, même si elle ne cite que trop rarement ses propres sources. On sait que Fournier a emprunté par exemple à l'Histoire de la Nouvelle France de Marc Lescarbot, à l'Histoire universelle des Indes occidentales et orientales et de la conversion des Indiens de Cornelius van Wytfliet et Antoine Magin ou encore au Traité de la navigation de Pierre Bergeron, mais il ne nous renseigne pas ici sur la provenance de ses informations sur les Parmentier. Aurait-il eu accès à des documents dieppois perdus aujourd'hui?

Le voyage à Sumatra est également cité : «Depuis ils firent encor un voyage en Guinée, au Cap de bonne Esperance, \& aux Moluques » ${ }^{172}$. Si le

167 Cité dans J. Parmentier, Euvres poétiques, F. Ferrand (éd.), p. 120.

168 P. CRignon, « Prologue », p. 3.

169 Jean et Raoul Parmentier avaient-ils un frère qui les aurait accompagnés au Brésil mais pas à Sumatra?

170 G. Fournier, Hydrographie contenant la theorie et la practique de toutes les parties de la navigation, Paris, chez Michel Soly, 1643, p. 321.

171 Né à Caen en 1595 et mort à La Flèche en 1652, il a enseigné les mathématiques au collège de la Flèche (notamment à René Descartes). En 1633, il entre au service de l'archevêque de Bordeaux Henri de Sourdis, aux côtés duquel, en tant qu'aumônier de la Marine royale, il navigue cinq ans (1636-1641). Il prend part à des opérations dans l'Atlantique et en Méditerranée durant la guerre contre l'Espagne, jusqu'en 1641 lorsque son protecteur est disgracié par Richelieu.

172 G. Fournier, Hydrographie, p. 321. 
récit de l'expédition ne mentionne qu'une escale de trois jours dans l'archipel du Cap-Vert (25-27 avril 1529) ${ }^{173}$, on peut considérer que celui-ci était englobé dans la dénomination très large de "Guinée » car il était une escale habituelle sur la route du Brésil où les Normands se rendaient régulièrement depuis les toutes premières années du XVI ${ }^{\mathrm{e}}$ siècle. Une interprétation hâtive de ce passage a certainement contribué à assimiler Jean Parmentier au « grand capitaine », et Fournier, qui connaissait peut-être le recueil de Ramusio, a pu être le premier à le faire.

D'autres auteurs l'ont fait après lui, en extrapolant et en voyant plusieurs voyages là où il n'y en a en réalité que deux : au Brésil et à Sumatra. Toutefois, on ne peut pas exclure totalement que Jean Parmentier se soit rendu également en Amérique du Nord et en Guinée, deux destinations fréquentes pour les navires normands dans les années 1520. Mais ces voyages auraient sûrement été mentionnés par Crignon, qui n’aurait pas manqué de mettre en avant la très large expérience de son ami, à moins qu'il ait voulu seulement insister sur le rôle de précurseur qu'il a joué au Brésil, rarement mentionné ailleurs sinon par Fournier et ceux qui l'ont repris par la suite. Il reste possible également que Crignon n'ait pas jugé utile de parler d'éventuels voyages de son ami en Amérique du Nord et en Guinée, justement parce que ces destinations étaient banales. L'idée d'un éventuel voyage sur les côtes nord-américaines, qui reste donc plausible, est peut-être tirée d'un économiste du XVII ${ }^{\mathrm{e}}$ siècle, Jacques Savary. Dans son manuel de commerce intitulé Le parfait négociant (1675), il ne cite pas ses sources, même s'il reprend certainement ici Fournier, mais en évoquant en plus un voyage « vers le Cap Breton », avec toutefois une confusion de taille qui laisserait croire qu'en fait il ne voulait peut-être parler que d'un voyage au Brésil : «En l'année 1520. trois freres appellez les Parmentiers, découvrirent vers le Cap Breton l'Isle de Fernanbourg, où ils chargerent leurs vaisseaux de riches marchandises; \& ensuite ils firent encore un voyage en Guinée, \& aux Moluques ${ }^{174}$. Savary n'est pas forcément une source très fiable ${ }^{175}$, mais il a été souvent repris. Il est cité par exemple, dans son édition du Discours de la navigation de Jean et Raoul Parmentier, par Charles Schefer, qui n'hésite pas à attribuer le Discours d'un grand capitaine à Pierre Crignon, que celui-ci aurait lui-même envoyé à Ramusio ${ }^{176}$.

173 Édition Estancelin, p. 244-249 ; édition Margry, p. 174-176 ; édition Schefer, p. 12-17 ; édition Nothnagle, p. 15-18.

174 J. Savary, Le parfait négociant, Paris, chez Jean Guignard fils, 1675, livre second, p. 114. Une édition critique a été réalisée récemment par É. Richard (Genève, Droz, 2011, 2 vol.).

175 Par exemple, il attribue par erreur au capitaine honfleurais Jacques Lelièvre un voyage vers les Indes orientales en 1616 ou 1617 (ibid., p. 115), en faisant une confusion avec les voyages d'Augustin de Beaulieu à Java et Sumatra entre 1616 et 1622. Voir E. GuÉnin, « La fin d'un corsaire honfleurais, le capitaine Lelièvre ", Le pays normand, mars-avril 1902, p. 33-47 et 56-62, où Savary est qualifié d'« écrivain fort sujet à caution » (p. 33).

176 Le discours de la navigation..., C. Schefer (éd.), p. IX, n. 1 et p. XXIV. 


\section{CONCLUSION}

Le Discours d'un grand capitaine reste un texte complexe et assez mystérieux, notamment sur l'identité de son auteur et du « grand capitaine ». Nous ne prétendons pas ici trancher définitivement, ni apporter des réponses complètement satisfaisantes, mais simplement émettre des hypothèses, soulever des questions et ouvrir des perspectives.

Selon nous, ce document a été rédigé en janvier 1539, dans un contexte de réaction et de contestation par rapport aux interdictions royales répétées de commercer au Brésil, en Guinée et dans toutes les zones théoriquement réservées aux Portugais. Il a été commandité par un groupe de puissants marchands normands qui souhaitaient maintenir et développer leur commerce avec ces régions. Le port de Rouen était alors le plus important du royaume, en connexion étroite avec ses satellites côtiers comme Dieppe et Honfleur, et les marchands rouennais, en particulier, menaient « une violente campagne en faveur de la liberté des mers $"{ }^{177}$. Ils cherchaient, de manière argumentée, à convaincre François $I^{\text {er }}$ de modifier sa politique en s'opposant aux prétentions portugaises, comme il l'avait déjà fait par le passé.

La partie introductive a pu être demandée à un pilote ou à un «astrologue » afin de démontrer l'étendue des connaissances cosmographiques acquises et maitrisées par les marins normands, qui les mettent en capacité de parcourir toutes les mers du globe. Pour la suite du texte, consacrée à l'Amérique du Nord, au Brésil et à la Guinée, l'auteur a pu collecter des informations précises auprès de divers capitaines et pilotes normands - ou étrangers comme les frères Verrazano - qui ont visité personnellement et à des périodes plus ou moins récentes les régions décrites, fréquentées régulièrement et dont la route est maîtrisée de longue date. Sont ainsi mises en avant l'expérience déjà acquise, ainsi que les connaissances accumulées sur le plan géographique, mais aussi sur les populations. La présence, ou plutôt l'absence, des Portugais est signalée : ils ne sont établis solidement qu'à Pernambouc et à Saint-Georges de la Mine ; cela induit qu'ailleurs, la voie est libre. Quant à la primauté de la découverte, l'auteur l'attribue logiquement à ses compatriotes (Bretons ou Normands), afin de contrer le principal argument des Portugais, dont les prétentions sont violemment critiquées à la fin de la partie sur le Brésil.

Le message est clair : les Français, et les Normands en particulier, ont déjà largement pris pied dans ces régions où ils ont devancé leurs concurrents portugais. Ils y ont établi de bonnes relations commerciales avec des populations accueillantes et beaucoup mieux disposées envers eux. Avec les informations géographiques réunies, ils disposent d'un véritable routier pour s'y repérer et s'y déplacer. Ils sont donc en mesure, non seulement de s'y maintenir, mais

177 M. Mollat, Le commerce maritime normand..., op. cit., p. 474. 
aussi d'y étendre leur commerce ; ils ont seulement besoin de l'autorisation du roi.

Pour la dernière partie sur Sumatra, l'auteur a pu solliciter un autre participant à l'expédition du Sacre et de la Pensée que Pierre Crignon; moins de dix ans après le retour des deux navires, il en restait forcément. On a évoqué une hypothèse fragile : il pourrait s'agir de Pierre Mauclerc, l'astrologue du Sacre. C'est une idée qu'on ne peut pas écarter, mais malheureusement nous ne savons rien de lui. Comme son homologue Crignon, il faisait partie des officiers et tenait un rôle important qui ne se réduisait pas à la navigation, d'autant plus après la mort des deux capitaines. En effet, les deux astrologues font alors partie des six hommes qui dirigent les discussions sur la suite à donner à leur voyage, aux côtés du maître du Sacre, non nommé, de Guillaume Sapin, contremaître de la Pensée, de Jean Leroux, dont la fonction n'est pas indiquée, et d'Antoine de la Sarde, le pilote portugais du Sacre. Hormis ce dernier, les trois autres personnages cités pourraient tout aussi bien être notre témoin. Il faut également prendre en compte que chaque marin rentré à Dieppe était a priori en mesure de relater oralement leur séjour à Ticou. Cela dit, le ton par moments très personnel employé ${ }^{178}$ indique que l'auteur est certainement un officier, un " haut gradé ", même si l'extrait «le premier dont les deux navires de Dieppe ont eu connaissance » (fol. 432) est ambigu, mais il peut s'agir là simplement d'une difficulté de traduction. Quant aux informations géographiques générales données sur Sumatra, soit elles viennent bien d'un des deux astrologues, soit elles peuvent provenir du pilote portugais, ou encore d'une carte portugaise.

Dans le contexte de contestation des interdictions royales, on peut aussi envisager que ce témoin ait livré une version "édulcorée » du voyage, en passant sous silence tous les éléments négatifs, en particulier les difficultés avec les indigènes pour le commerce ainsi que la mort des deux capitaines et de nombreux marins. On pourrait ici établir un parallèle avec l'expédition du Corbin et du Croissant, menée soixante-dix ans plus tard jusqu'à la même île de Sumatra (1601-1603). Le croisement des différentes sources a permis de démontrer que l'une d'elles, le récit de François Martin, n'a volontairement conservé que les éléments positifs de son expérience et a minimisé les difficultés, pourtant nombreuses, rencontrées par les équipages. Son très court ouvrage, intitulé Description du premier voyage faict aux Indes Orientales par les François en l'An 1603, passe sous silence ou modifie sciemment certains faits. Commandé par Henri IV, il a été clairement orienté afin de servir les projets ambitieux du roi, c'est-à-dire développer le commerce de la France avec les lointaines îles aux épices. En effet, peu après la publication du livre

178 Surtout le passage « Je n'ai eu affaire dans tout ce lieu et sous ce roi qu'à deux officiers » (fol. 432). 
de Martin, fut créée la première Compagnie française des Indes orientales, le $1^{\text {er }}$ juin $1604^{179}$.

Dans les deux cas, l'objectif est d'encourager de nouvelles expéditions, de motiver de potentiels investisseurs et surtout de ne pas les effrayer. Pour ce qui concerne le Discours d'un grand capitaine, les marchands normands ont la ferme intention de poursuivre leur commerce dans les zones théoriquement réservées aux Portugais - c'est le cas des Indes orientales - et ils ont intérêt à passer sous silence les problèmes rencontrés précédemment. Au contraire, ils tiennent à montrer qu'ils sont capables de mener ces expéditions lointaines. Ce témoignage, orienté et subjectif, vise à prouver qu'ils se sont déjà rendus à Sumatra et à faire croire que le voyage s'est très bien passé. De plus, ils n'ont pas rencontré de Portugais : l'expérience peut ainsi être renouvelée. Cela permettrait d'accéder à de nouveaux marchés forcément lucratifs, d'ouvrir à la France la route des épices et des autres précieuses richesses des Indes orientales par la route du cap de Bonne-Espérance, au lieu de subir le monopole portugais ou de se les procurer par la route antique contrôlée par les Turcs puis les Vénitiens, donc dans les deux cas les acheter à prix d'or à des intermédiaires onéreux. Voilà autant d'arguments qui visent à convaincre François $\mathrm{I}^{\mathrm{er}}-$ qui aurait bien besoin de trouver de nouvelles sources de revenus dans sa lutte contre Charles Quint ${ }^{180}$ - de lever ses interdictions et de « lâcher la bride aux marchands de son pays" (fol. 426v).

$\mathrm{Au}$-delà des hypothèses et des pistes de réflexion proposées, bien des questions restent en suspens, et notamment pourquoi ne pas avoir mentionné le nom du " grand capitaine »? Simplement peut-être parce que, comme nous avons tenté de le démontrer, ce texte est une sorte de compilation - pratique extrêmement fréquente au $\mathrm{XVI}^{\mathrm{e}}$ siècle et tout particulièrement dans la littérature hodéporique et géographique -, une somme, un état des connaissances, et que toutes ces informations ont été recueillies au cours de multiples voyages effectués par de nombreux capitaines différents. Même si la dernière partie fait certainement référence à l'expédition commandée par Jean Parmentier, pourquoi mettre en avant son nom plus que celui d'un autre capitaine ? L'idée était sans doute de démontrer les capacités des marins normands / dieppois en général et non pas seulement celles de l'un des leurs, certes peut-être le plus célèbre d'entre eux, mais qui était mort des fièvres à Sumatra ; un fait qu'il valait mieux dissimuler.

179 Voir ma thèse soutenue en février 2014 à l'université de Caen : Les précurseurs de la Compagnie française des Indes orientales, 1601-1622 (disponible sur HAL ; à paraître aux Presses universitaires de Caen, sous le titre Les Français dans la course aux épices, 1601-1622).

180 Même si en 1538 le roi de France et l'empereur avaient signé la trêve de Nice puis s'étaient réconciliés lors de l'entrevue d'Aigues-Mortes, la paix n'était que provisoire et les hostilités reprirent en 1542. 
Un autre point demeure obscur : comment expliquer que sur la carte de Taprobane / Sumatra (fol. 433-434) ${ }^{181}$ figurent des toponymes qui ne sont pas mentionnés dans le Discours d'un grand capitaine mais qui ne se trouvent que dans le récit des Parmentier, rédigé par Pierre Crignon ? Dans ce dernier, les îles rencontrées avant d'accoster à Ticou sont nommées "l'isle Parmentiere ", la Louise et la Marguerite ${ }^{182}$, en l'honneur de Louise de Savoie et de Marguerite de Navarre, la mère et la sœur de François I $^{\text {er }}$ On les retrouve sur la carte - seul témoignage cartographique qui les mentionne - à côté de deux navires aux voiles fleurdelysées, sous les formes italianisées La formetiera, La margarite et La lauyse. Elles sont accompagnées, entre autres, par les dénominations des points de la côte où ont abordé les Dieppois : «Ticou », «Priame », «Indapoure » et "Selagam », toutes citées dans le récit de Crignon mais pas dans le Discours d'un grand capitaine (sauf Ticou).

Le même cas de figure se présente pour la carte de La Nuova Francia (fol. 424-425) $)^{183}$ : des noms comme "Angoulesme » ou " Port du Refuge » ne se trouvent pas dans la Relation (incomplète) de Verrazano publiée par Ramusio juste avant le Discours d'un grand capitaine, mais seulement, dans l'état actuel de nos connaissances, dans le manuscrit Cèllere déjà évoqué, découvert en $1909^{184}$.

Dans le Discorso sopra il terzo volume, Ramusio désigne Gastaldi comme étant l'auteur de la carte du continent américain intitulée Universale della parte del mondo nuovamente ritrovata située en toute fin de volume (fol. 455456 ${ }^{185}$. Cet universale aurait été divisé en quatre pour créer d'autres cartes à plus grande échelle, mais là se pose un problème de correspondance : ces « quattro tavole " ${ }^{186}$ pourraient être les cartes de La Nuova Francia (fol. 424425), du Brésil (fol. 427-428), et pourquoi pas celle de l'Afrique occidentale (fol. 430-431), même si celle-ci n’apparaît que très peu sur l'universale. Mais Taprobane / Sumatra, elle, n'y figure pas du tout.

Un peu plus bas, Ramusio évoque les « alcuni Eccellenti huomini Francesi» qui ont envoyé à Fracastor (ou à lui directement) les relations sur la Nouvelle France. Si leur identité ainsi que la façon dont ils ont acquis ces textes restent elles

181 https://digi.ub.uni-heidelberg.de/diglit/ramusio1556bd3/0946/image.

182 Ces trois îles, aujourd'hui nommées Tanahbala, Tanahmasa et Pini, font partie de l'archipel des Batu, situé entre l'île de Nias au nord et celle de Siberut au sud, à environ une centaine de kilomètres en face de Ticou (Tiku).

183 https://digi.ub.uni-heidelberg.de/diglit/ramusio1556bd3/0931/image.

184 Voir J. Habert, M. Mollat du Jourdin, Giovanni et Girolamo Verrazano..., op. cit., p. 4-6, 11 et 179. La version incomplète publiée par Ramusio a été traduite en français par le général Langlois dans le même ouvrage où il a traduit le Discours d'un grand capitaine: G.B. RAmusio, À la découverte de l'Amérique du Nord. Navigations et voyages (XVI' siècle), op. cit., p. 95-108.

185 https://digi.ub.uni-heidelberg.de/diglit/ramusio1556bd3/0986/image.

186 «Messer Iacomo de' Gastaldi cosmografo eccellente, n'ha ridotto in piccol compasso vno vniversale, \& poi quello in quattro tavole diviso [...]» (Discorso sopra il terzo volume delle navigationi, et viaggi nella parte del mondo nuovo indirizzato, vol. III, 1556, fol. 5v). 
aussi des mystères, ils ont transmis en même temps quatre « dessins / cartes [disegni], qui seront placé(e)s dans ce volume en leurs lieux ${ }^{187}$. Ne pourrait-il pas s'agir ici des quatre cartes qui illustrent le Discours d'un grand capitaine de Dieppe ? Chacune d'elles se trouve justement située au niveau des parties du texte correspondant géographiquement. Le projet initial aurait donc été modifié - et la dédicace n'aurait pas été actualisée - suite à la réception de ces quatre « disegni $i$ en provenance de France, et peut-être plus précisément de Dieppe. En effet, comme l'a avancé récemment l'une des plus grandes spécialistes de Ramusio, M. Milanesi, Gastaldi aurait suivi un modèle dieppois ${ }^{188}$. Même si, plus largement, sa démarche consistait à compiler de nombreuses sources différentes ${ }^{189}$, il paraît évident que, particulièrement pour les cartes de $L a$ Nuova Francia et de Sumatra (cela est moins net pour les deux autres), il s'est inspiré de ces « disegni » français / dieppois où devaient inévitablement figurer les informations et les toponymes contenus dans les récits de Verrazano (dans sa version complète) et de Crignon.

Toutefois, on ne peut pas exclure totalement que Ramusio ait disposé de ces deux textes, sans pour autant les insérer dans son recueil. Dans le premier cas, il aurait pu choisir d'en publier la version « allégée » afin de ne pas embarrasser le lecteur avec des considérations jugées trop techniques ou mathématiques. Il semble en effet qu'il connaissait la partie cosmographique de la Relation, puisqu'il aurait eu en main un manuscrit encore conservé au $\mathrm{xx}^{\mathrm{e}}$ siècle par l'académie de Cimento qui la contient ${ }^{190}$.

Dans le second cas, Ramusio n'aurait pas publié le récit de l'expédition du Sacre et de la Pensée peut-être parce que, comme on l'a vu, il a souhaité donner à l'ensemble de son recueil, en plus d'une cohérence linguistique et spatiale, une homogénéité géopolitique et épistémologique, en mettant en avant trois grandes puissances : Venise, le Portugal et l'Espagne. Même s'il y a des exceptions notables, comme la partie du troisième volume consacrée à la Nuova Francia, où se trouvent le Discours d'un grand capitaine ainsi que trois autres récits « français » (le premier voyage de Verrazano et les deux premiers de Cartier), Ramusio a pu estimer que ceux-ci se justifiaient car ils étaient les seuls dont il disposait à apporter des connaissances sur la côte nord-américaine. Au contraire, selon lui, la relation du premier voyage français à Sumatra

187 «Il simile fanno alcuni Eccellenti huomini Francesi, che da Parigi le hanno mandato le relationi della Nuoua Francia con quattro disegni insieme, che saranno posti in questo volume à suoi luoghi »(ibid.).

188 M. Milanesi, « Ramusio : la synthèse des savoirs sur l'océan », Topoi. Orient-Occident, supplément $\mathrm{n}^{\circ}$ 15, 2017, Méditerranée et océan Indien. Deux mondes en miroir, D. MarcotTe (éd.), p. 252 : «Bien que le modèle des cartes dressées par Gastaldi pour les Navigazioni soit très clairement dieppois ».

189 Cette synthèse serait l'une des raisons de la pérennité de ses cartes. Voir M. MilanESI, « El mundo visto desde Venecia en el siglo XVI. Ramusio y Gastaldi », El mundo de las mapas. Cuadernos de la Fundación M. Botin, n 7, 2005, p. 131-160.

190 Voir J. Habert, M. Mollat du Jourdin, Giovanni et Girolamo Verrazano..., op. cit., p. 6, qui renvoient à A. BACCHIANI, « I Fratelli de Verrazano e l'eccidio di una spedizione italo-francese in America (1528) », Bolletino della Societá geografica italiana, 1925, p. 375. 
n'avait peut-être pas sa place dans son œuvre, dans la mesure où il avait déjà publié dans le premier volume plusieurs récits sur les Indes orientales, qui avaient en plus le mérite d'être des sources portugaises ou « italiennes » (Vasco de Gama, Cabral, Ludovico di Varthema, Giovanni da Empoli...). En outre, il a sans doute reçu de nombreux manuscrits, mais il ne pouvait pas tous les publier : il était contraint d'opérer une certaine sélection sinon son recueil, déjà imposant, aurait été trop volumineux.

\title{
Résumé
}

Le Discours d'un grand capitaine de Dieppe. Traduction et édition d'un document normand de 1539 - Le Discours d'un grand capitaine de Dieppe (1539) contient des descriptions de quatre territoires aussi différents que la côte de l'Amérique du Nord, celle du Brésil, celle de l'Afrique du cap Vert au Congo (la " Guinée »), et l'île de Sumatra. Il est révélateur des connaissances et de l'expérience acquises par les Normands dans le premier tiers du XVI siècle sur ces régions. Connu grâce à une version italienne publiée en 1556 par G.B. Ramusio dans ses Navigationi et viaggi, il a fait l'objet de plusieurs éditions-traductions en français et en anglais. Ce document riche mais énigmatique, mal connu, n'est plus utilisé par l'historiographie depuis longtemps. Une nouvelle traduction a permis de mener une nouvelle analyse critique de son contenu, permettant d'aboutir à des hypothèses sur la datation et le contexte de rédaction, ainsi que sur l'identification de l'auteur et du fameux " grand capitaine de Dieppe ». Cette contribution constitue l'étude historique liée à l'édition numérique $\mathrm{du}$ texte, avec une annotation scientifique.

Mots clés : Discours d'un grand capitaine de Dieppe - Ramusio - Amérique du Nord - Brésil - Guinée - Sumatra - édition numérique.

\begin{abstract}
The Discourse of a Great Captain of Dieppe. Translation and edition of a norman document of 1539 - The Discourse of a Great Captain of Dieppe (1539) contains descriptions of four territories as different as the coast of North America, that of Brazil, that of Africa from Cape Verde to Congo (the "Guinée"), and the island of Sumatra. It is indicative of the knowledge and experience acquired by the Normans in the first third of the sixteenth century on these regions. Known thanks to an Italian version published in 1556 by G.B. Ramusio in his Navigationi et viaggi, it has been the subject of several editions-translations in French and English. This rich but enigmatic, poorly known document has not been used by historiography for a long time. A new translation has led to a new critical analysis of its content, leading to hypotheses about dating and the context of writing, as well as the identification of the author and the famous "great captain of Dieppe". This contribution constitutes the historical study related to the digital edition of the text, with a scientific annotation.
\end{abstract}

Keywords : Discourse of a Great Captain of Dieppe - Ramusio - North America Brazil - Guinea - Sumatra - digital edition. 


\section{Annales}

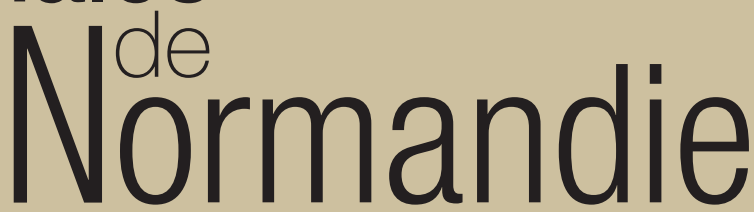

Revue semestrielle d'études régionales

Stéphane Lecouteux, À la recherche des livres du Bec. Deuxième partie : Claude Antoine Le Marchants de Cambronne (1742-1836)

Camille Bataille, La Visitation, témoin de la réception liturgique: une comparaison entre la province d'Uppsala et la province de Rouen (fin XV - milieu du XVI siècle)

Guillaume Lelièvre, Le Discours d'un grand capitaine de Dieppe. Traduction et édition d'un document normand de 1539

Jean-Marc Lemonnier et Frédéric Dutheil, Des patronages rouennais aux rives de l'Orne: Jean Calbrix, itinéraire d'un randonneur hébertiste depuis les années 1930

\section{Sources et documents}

Michel Daeffler, La guerre d'Indépendance des États-Unis sur les murs du prieuré Saint-Gabriel (1775-1783). Une scène maritime gravée dans la «salle de justice »

\section{Compte rendu de soutenance de thèse}

Baptiste Étienne, Rouen en 1650 : carrefour des conflits (Loup Guesnon)

Photo de couverture :

G. B. Ramusio, Terzo volume delle navigationi et viaggi, Venetia, 1556, carte de Sumatra, p. 433-434, détail, Universität Heildelberg.

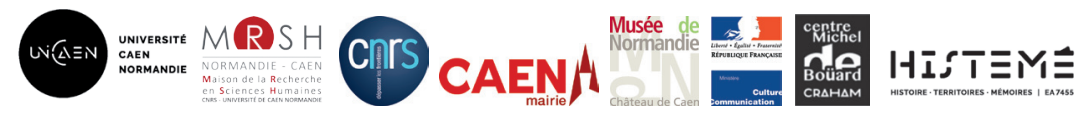

